\title{
LIS1 Deficiency Promotes Dysfunctional Synaptic Integration of Granule Cells Generated in the Developing and Adult Dentate Gyrus
}

\author{
Robert F. Hunt, Matthew T. Dinday, William Hindle-Katel, and Scott C. Baraban \\ Epilepsy Research Laboratory, Department of Neurological Surgery, University of California, San Francisco, San Francisco, California 94143
}

Type I lissencephaly, a neuronal migration disorder characterized by cognitive disability and refractory epilepsy, is often caused by heterozygous mutations in the LIS1 gene. Histopathologies of malformation-associated epilepsies have been well described, but it remains unclear whether hyperexcitability is attributable to disruptions in neuronal organization or abnormal circuit function. Here, we examined the effect of LIS1 deficiency on excitatory synaptic function in the dentate gyrus of hippocampus, a region believed to serve critical roles in seizure generation and learning and memory. Mice with heterozygous deletion of LIS1 exhibited robust granule cell layer dispersion, and adult-born granule cells labeled with enhanced green fluorescent protein were abnormally positioned in the molecular layer, hilus, and granule cell layer. In whole-cell patch-clamp recordings, reduced LIS1 function was associated with greater excitatory synaptic input to mature granule cells that was consistent with enhanced release probability at glutamatergic synapses. Adult-born granule cells that were ectopically positioned in the molecular layer displayed a more rapid functional maturation and integration into the synaptic network compared with newborn granule cells located in the hilus or granule cell layer or in wild-type controls. In a conditional knock-out mouse, induced LIS1 deficiency in adulthood also enhanced the excitatory input to granule cells in the absence of neuronal disorganization. These findings indicate that disruption of LIS1 has direct effects on excitatory synaptic transmission independent of laminar disorganization, and the ectopic position of adult-born granule cells within a malformed dentate gyrus critically influences their functional maturation and integration.

\section{Introduction}

Type I lissencephaly attributable to mutations in lis 1 is a malformation of cortical development (MCD) with high incidence of intractable epilepsy and intellectual disability (Reiner et al., 1993). LIS1 protein interacts with components of the microtubule network in which it plays important roles in neuronal proliferation and migration during cortical development (Wynshaw-Boris et al., 2010). Mice with a heterozygous deletion of lis1 (i.e., LIS1 mutants) exhibit delayed neuronal migration, disorganization of cortical and hippocampal cell layers, deficits in hippocampal-dependent learning behaviors, and spontaneous electrographic seizures (Hirotsune et al., 1998; Paylor et al., 1999; Fleck et al., 2000; Wang and Baraban, 2007, 2008; Greenwood et al., 2009).

Neuronal disorganization in MCD is thought to underlie abnormal hyperexcitability (Leventer et al., 2008). However, sei-

\footnotetext{
Received March 15, 2012; revised July 13, 2012; accepted July 19, 2012.

Author contributions: R.F.H. and S.C.B. designed research; R.F.H., M.T.D., and W.H.-K. performed research; R.F.H. and S.C.B. analyzed data; R.F.H. and S.C.B. wrote the paper.

This work was supported by funding from National Institutes of Health Grant NS040272-10 (S.C.B.). We thank A. Wynshaw-Boris for generous donation of LIS1 mutant and conditional knock-out mice and J. Rubenstein for Cre reporter mice. We also thank K. Girskis for mouse genotyping.

Correspondence should be addressed to Dr. Robert F. Hunt III, Epilepsy Research Laboratory, Department of Neurological Surgery, Box 0520, University of California, San Francisco, 513 Parnassus Avenue, San Francisco, CA 94143. E-mail: Robert.Huntiii@ucsf.edu.

DOI:10.1523/JNEUROSCI.1286-12.2012

Copyright $\odot 2012$ the authors $\quad 0270-6474 / 12 / 3212862-14 \$ 15.00 / 0$
}

zures can originate from brain regions outside of the dysplastic tissue (Jacobs et al., 2009), and tissue sections from patients with genetically confirmed MCD (without gross anatomical defects) are capable of abnormal synchronous activity (Wang et al., 2007). Recent evidence revealed premature expression of synaptogenesis and synaptic contact genes during development in LIS1 mutant mice (Pramparo et al., 2011). Morphological and functional alterations of the hippocampal Schaffer collateral-CA1 synapse in LIS1 mutants was shown to be associated with enhanced excitability in pyramidal neurons (Fleck et al., 2000; Greenwood et al., 2009). Therefore, LIS1 might play a significant role in normal synaptic transmission, even in mature neurons. However, it is unclear how reduced LIS1 function contributes to an epileptic phenotype or whether an LIS1-mediated synaptic pathophysiology can be observed in the absence of developmental abnormalities leading to laminar disorganization.

Previous work from our laboratory demonstrated that LIS1 mutants exhibit granule cell layer dispersion and aberrant neurogenesis in the dentate gyrus (DG) (Wang and Baraban, 2007, 2008) e.g., a pattern of laminar disorganization reminiscent of human temporal lobe epilepsy (Houser, 1990). The adult DG generates new neurons that migrate and integrate into an existing hippocampal circuitry-a process sensitive to environmental factors (Kempermann et al., 1997; Tashiro et al., 2007) and local network activity (Piatti et al., 2011). Moreover, disrupting adult neurogenesis may support seizure generation (Parent et al., 1997) or modify cognition (Arruda-Carvalho et al., 2011). Although 

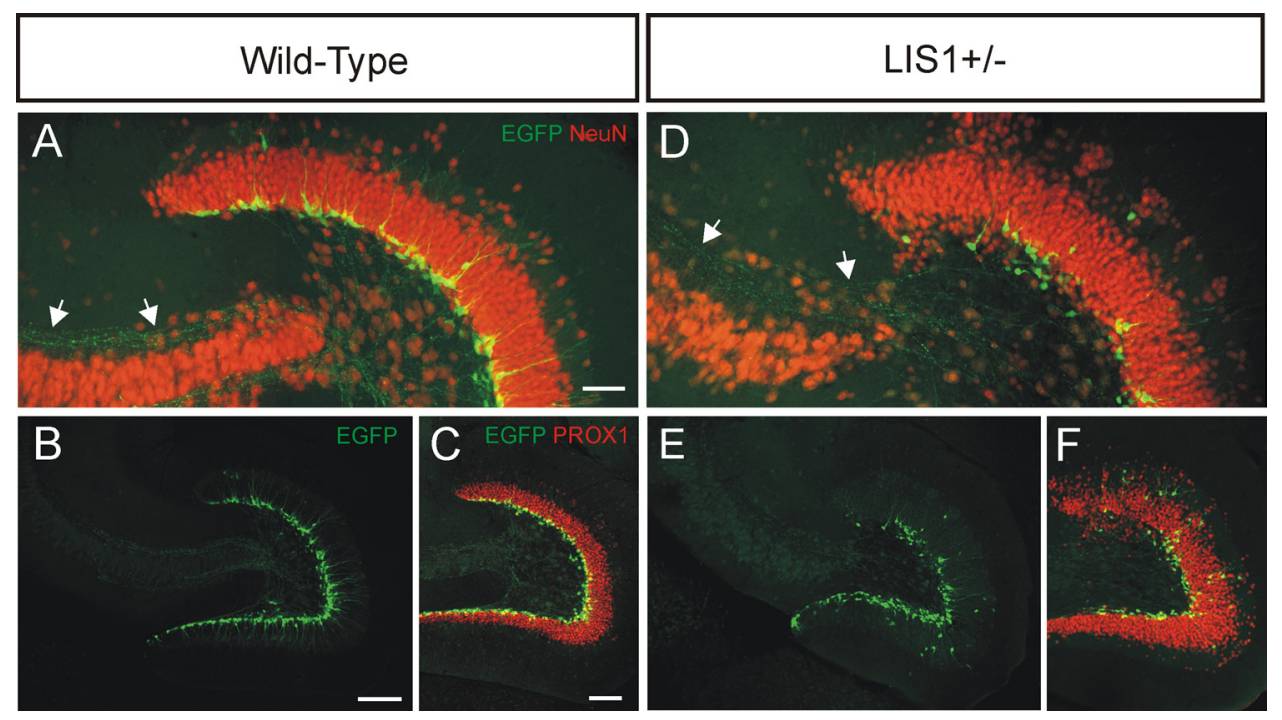

Figure 1. Granule cell displacement in LIS1 mutant mice. $A$, Confocal image of EGFP-labeled newly born granule cells (green) and NeuN immunostaining (red) in a wild-type animal. Arrows indicate EGFP-labeled mossy fibers projecting toward stratum lucidum of CA3. B, Low-magnification image of EGFP staining of the same section shown in A. C, EGFP and PROX1 (red) staining in a wild-type mouse. D, EGFP and NeuN immunostaining shows loosely packed principal cell layers in an LIS1 mutant. Arrows in D indicate EGFP-labeled mossy fibers projecting toward stratum lucidum of CA3. $\boldsymbol{E}$, Low-magnification image of EGFP staining of the same section shown in $\boldsymbol{D}$. F, EGFP and PROX1 staining shows displacement of granule cells into the hilus and molecular layer of a LIS1 mutant mouse. Scale bars: $A, D, 50 \mu \mathrm{m} ; \boldsymbol{B}, \boldsymbol{E}, 167 \mu \mathrm{m} ; \boldsymbol{C}, \boldsymbol{F}, 100 \mu \mathrm{m}$.

synaptic inputs to adult-born neurons in the normal brain are well described (Laplagne et al., 2006), there is a lack of information regarding functional development of newborn granule cells within a malformed hippocampus. Interestingly, acquired epilepsy models are often associated with enhanced proliferation of newborn granule cells (Parent et al., 1997; Overstreet-Wadiche et al., 2006), but adult-born granule cell survival is reduced in LIS1 mutants (Wang and Baraban, 2007). Because dysplastic neurons can also exhibit delayed synaptic maturation (Ackman et al., 2009) and sometimes fail to integrate into functional networks (Cepeda et al., 2003), the synaptic integration of adult-born granule cells might be different in epilepsies associated with an MCD. To address these issues, we used LIS1 mutant, enhanced green fluorescent protein (EGFP) reporter, and conditional knock-out mice in a series of immunohistochemical and electrophysiological studies.

\section{Materials and Methods}

Animals. LIS1 ${ }^{+/-}$mice (Hirotsune et al., 1998; Jones and Baraban, 2007, 2009; Wang and Baraban, 2007, 2008; Greenwood et al., 2009) were mated with hemizygous pro-opiomelanocortin-EGFP (POMC:EGFP) transgenic mice [C57BL/6J-Tg(Pomc-EGFP)1Low/J; The Jackson Laboratory; Cowley et al., 2001] to produce $L I S 1^{+/-}, P O M C: E G F P$ mice. In a separate set of experiments, hypomorphic conditional knock-out mice (i.e., LIS1 $1^{+/ c K O}$ or Pafah1b1-loxP; Hirotsune et al., 1998; a gift from Anthony Wynshaw-Boris, University of California, San Francisco (UCSF), San Francisco, CA) were mated with CreER mice [Tg(CAGCre/Esr1)5Amc/J; The Jackson Laboratory] and a CAG-CAT-EGFP Cre reporter (Kawamoto et al., 2000; a gift from John Rubenstein, UCSF, San Francisco, CA). To induce Cre-mediated recombination, tamoxifen (Sigma-Aldrich) was prepared in corn oil (Sigma-Aldrich) at a concentration of $40 \mathrm{mg} / \mathrm{ml}$ and administered to 6-week-old LIS1 $^{+/ c K O}$; CreER mice at a dose of $4 \mathrm{mg} / \mathrm{d}$ for 4 consecutive days. Water and food were available ad libitum. Mice were bred in house, and all procedures were first approved by the University of California, San Francisco Animal Care and Use Committee and adhered to National Institutes of Health Guidelines for the Care and Use of Laboratory Animals. Experiments were performed on 6- to 8-week-old male and female littermates or 6 weeks after tamoxifen administration. No significant gender differences were observed.
Immunocytochemistry. Animals were deeply anesthetized with ketamine/xylazine administration and perfused transcardially with $4 \%$ paraformaldehyde (PFA) in $0.1 \mathrm{~m}$ PBS, pH 7.4. Brains were removed and postfixed overnight in the same solution. Free-floating vibratome sections $(50 \mu \mathrm{m})$ were processed using standard immunostaining procedures. Primary antibody dilutions were as follows: chicken anti-GFP (1:500; Aves); rabbit anti- prospero homeobox protein 1 (PROX1) (1: 500; Millipore); mouse anti-neuronal nuclear protein (NeuN) (1:500; Millipore); and guinea pig anti-doublecortin (DCX) (1:200; Millipore). Secondary antibodies included Alexa Fluor 488 and Alexa Fluor 594. Sections were then mounted on charged slides (Superfrost plus; Thermo Fisher Scientific) with Vectashield that contained DAPI. Images were obtained using a Yokogawa CSU-X1 Borealis spinning disk confocal microscope (Nikon).

Timm's staining. Animals were anesthetized with ketamine/xylazine administration, perfused transcardially with $0.37 \%$ sodium sulfide solution in $0.1 \mathrm{M} \mathrm{NaHPO}_{4}$, followed by $4 \%$ PFA in $0.1 \mathrm{M} \mathrm{PBS}$, and stored overnight in 4\% PFA solution. Brains were then cryoprotected in a $30 \%$ sucrose solution in PBS and sectioned at $20 \mu \mathrm{m}$ on a cryostat, and every sixth section was mounted on charged slides (Superfrost Plus; Thermo Fisher Scientific). Sections were dried overnight and treated according to previous protocols using Timm's stain to reveal mossy fibers and Nissl counterstained with cresyl violet to visualize cell bodies (Tauck and $\mathrm{Na}$ dler, 1985; Hunt et al., 2009, 2010). To semiquantitatively assess the presence or absence of mossy fiber sprouting into the inner molecular layer of the DG, Timm scores from 0 (little to no sprouting) to 3 (robust mossy fiber sprouting) (Tauck and Nadler, 1985; Hunt et al., 2009, 2010) were assigned to five randomly chosen sections and averaged for each animal. Regions of the DG with Timm scores $>1$ were considered to have an abnormal degree of mossy fiber sprouting (Tauck and Nadler, 1985; Hunt et al., 2009, 2010). Images were taken with a Carl Zeiss Axioskop microscope and captured with an Optronics Microfire camera.

Slice preparation. Mice were deeply anesthetized by ketamine/xylazine administration and decapitated. The brain was removed and immersed in ice-cold $\left(2-4^{\circ} \mathrm{C}\right)$ oxygenated high-sucrose artificial CSF (ACSF) containing the following (in $\mathrm{mm}$ ): 150 sucrose, $50 \mathrm{NaCl}, 25 \mathrm{NaHCO}_{3}, 10$ dextrose, $2.5 \mathrm{KCl}, 1 \mathrm{NaH}_{2} \mathrm{PO}_{4}-\mathrm{H}_{2} \mathrm{O}, 0.5 \mathrm{CaCl}_{2}$, and $7 \mathrm{MgCl}_{2}$, pH 7.2-7.4 (equilibrated with $95 \% \mathrm{O}_{2}-5 \% \mathrm{CO}_{2}, 300-305 \mathrm{mOsm} / \mathrm{kg}$ ). Brains were blocked and glued to a sectioning stage, and $300-\mu \mathrm{m}$-thick transverse slices were cut in ice-cold, oxygenated high-sucrose ACSF using a Vibratome (Leica VTS1000). Slices were cut in the horizontal plane to 
ensure consistency of transverse slices from the ventral half of the hippocampus. Slices were transferred to a storage chamber containing oxygenated ACSF [in mm: $124 \mathrm{NaCl}, 3 \mathrm{KCl}$, $1.25 \mathrm{NaH}_{2} \mathrm{PO}_{4}-\mathrm{H}_{2} \mathrm{O}, 2 \mathrm{MgSO}_{4}-7 \mathrm{H}_{2} \mathrm{O}, 26$ $\mathrm{NaHCO}_{3}, 10$ dextrose, and $2 \mathrm{CaCl}_{2}, \mathrm{pH} 7.2-7.4$ $(300-305 \mathrm{mOsm} / \mathrm{kg})]$, heated at $35^{\circ} \mathrm{C}$ for $\sim 45$ $\mathrm{min}$ in a water bath, and maintained at room temperature until used for experimentation.

Electrophysiology. After an equilibration period of at least $60 \mathrm{~min}$, slices were transferred to a recording chamber on an upright, fixed-stage microscope equipped with infrared, differential interference contrast and epifluorescence optics (Olympus BX50WI), where they were continuously perfused with warmed (34$35^{\circ} \mathrm{C}$ ) ACSF. Recordings were performed on granule cells found in the granule cell layer, and EGFP-labeled neurons were identified by epifluorescent illumination. Patch pipettes were pulled from borosilicate glass $(1.5 \mathrm{~mm}$ outer diameter and $0.45 \mathrm{~mm}$ wall thickness; World Precision Instruments) with a P-87 puller (Sutter Instruments). The intracellular solution contained the following: $140 \mathrm{mM} \mathrm{K}^{+}$gluconate, $1 \mathrm{~mm} \mathrm{NaCl}, 5 \mathrm{~mm}$ EGTA, $10 \mathrm{~mm}$ HEPES, $1 \mathrm{~mm} \mathrm{MgCl}$, $1 \mathrm{~mm} \mathrm{CaCl}_{2}, 3 \mathrm{~mm} \mathrm{KOH}$, 2 mM ATP, and $0.2 \%$ biocytin, $\mathrm{pH} 7.21$. For voltage-clamp recordings obtained from mature granule cells, $140 \mathrm{~mm} \mathrm{Cs}^{+}$gluconate was used in place of $\mathrm{K}^{+}$gluconate. Extracellular recording electrodes were filled with $1 \mathrm{~m} \mathrm{NaCl}$. Open tip resistance was 3-5 M . Recordings were obtained with an Axopatch 1D amplifier (Molecular Devices), filtered at $5 \mathrm{kHz}$, and recorded to pClamp 10.2 (Clampfit; Molecular Devices). After membrane rupture, cells were first voltage clamped for $\sim 5 \mathrm{~min}$ at $-70 \mathrm{mV}$ (i.e., near resting membrane potential) to allow equilibration of intracellular and recording pipette contents. Spontaneous (s), miniature (m), and evoked (e) EPSCs were examined at a holding potential of $-70 \mathrm{mV}$. Series resistance was typically $<15 \mathrm{M} \Omega$ and was monitored throughout the recordings. Data were only used for analysis if the series resistance remained $<20 \mathrm{M} \Omega$ and changed by $\leq 20 \%$ during the recordings. Recordings were not corrected for a liquid junction potential. Resting membrane potentials were measured immediately after breakthrough by temporarily removing the voltage clamp and monitoring voltage. For current-clamp recordings, cells were held at $-70 \mathrm{mV}$, and intrinsic electrophysiological properties were measured in response to a series of long (1000 ms) hyperpolarizing and depolarizing current injections ( $10 \mathrm{pA}$ steps; range, -80 to $210 \mathrm{pA}$ ). Input resistances $\left(R_{\text {input }}\right)$ were measured from peak voltage responses to $\pm 10 \mathrm{pA}$ current injections (1000 ms duration). We likely underestimated $R_{\text {input }}$ for some EGFPlabeled newly born granule cells, because $R_{\text {input }}>R_{\text {seal }}$. Membrane time constant $\left(\tau_{\mathrm{m}}\right)$ was calculated by fitting the voltage response to a -10 pA hyperpolarizing current pulse with a single exponential function:

$$
y=y_{0}+A e^{-t / \tau},
$$

where $y_{0}$ is the $y$ asymptote, $A$ is amplitude, $\tau_{\mathrm{m}}$ is decay time constant, and $t$ is time. Spike accommodation was identified by examining the ratio of the interspike intervals between the last two action potentials in the train compared with the first two at two times spike threshold. Input-output responses for each cell were measured by determining the slope of firing frequency versus injected current. Added to the ACSF for specific experiments were the following: tetrodotoxin (TTX) ( $2 \mu \mathrm{M}$; Sigma-Aldrich), bicuculline methiodide (BMI) (30 $\mu$; Sigma-Aldrich), and kynurenic acid (1 mM; Sigma-Aldrich). In some experiments, slices were perfused with $\mathrm{Mg}^{2+}$-free ACSF containing $30 \mu \mathrm{M}$ BMI to block $\mathrm{GABA}_{\mathrm{A}^{-}}$ receptor mediated recurrent inhibition and unmask NMDA- receptor mediated excitatory synapses at resting membrane potential (Hunt et al., 2009, 2010).

Electrical stimulation. A concentric bipolar stimulating electrode made of platinum-iridium wire (125 $\mu \mathrm{m}$ diameter; FHC) was used to apply single and paired stimuli to the perforant pathway or hilus. Stimulus pulses were delivered through a WPI A360 stimulus isolation unit with duration of $100 \mu \mathrm{s}$. The minimal intensity necessary to evoke a response at $-70 \mathrm{mV}$ was found, and then 20 consecutive responses were recorded at $0.1 \mathrm{~Hz}$. An assumption was not made about the number of synapses recruited by the stimuli. A series of graded stimuli was then applied by increasing the stimulus current at increasing multiples of the threshold for evoking detectable EPSCs (i.e., T, $2 \mathrm{~T}, 3 \mathrm{~T}, 5 \mathrm{~T}, 10 \mathrm{~T}, 15 \mathrm{~T}, 0.1 \mathrm{~Hz}$ ). Input-output responses for each cell were measured by determining the slope of EPSC amplitudes versus the normalize stimulus unit. In some experiments, pairs of stimuli were delivered to the perforant pathway at $2 \mathrm{~T}$ and a pairing interval of $40 \mathrm{~ms}$. For each trial, 10 consecutive responses were obtained at $0.1 \mathrm{~Hz}$ and averaged. Amplitudes of eEPSCs were measured from the baseline at which the stimulus was applied to the EPSC peak. For pairedpulse responses, the ratio of the amplitude of the second eEPSC to the first (eEPSC2/eEPSC1) was calculated to establish the paired-pulse ratio (PPR). All stimulations were recorded in the presence of $30 \mu \mathrm{M}$ BMI to block $\mathrm{GABA}_{\mathrm{A}}$ receptormediated events. For antidromic stimulation experiments, a single stimulus was delivered to the hilus, and stimulus intensity was adjusted to produce a population spike of $\sim 50 \%$ of maximum amplitude. Ten consecutive responses were obtained at $0.1 \mathrm{~Hz}$ and averaged.

Data analyses and statistics. Data analysis was performed using pClamp 10.2 (Clampfit; Molecular Devices), MiniAnalysis 6.0 (Synaptosoft), Microsoft Excel, and Instat (GraphPad Software) programs. A 2-5 min sample recording per cell was used for measuring EPSC frequency, amplitude, 10-90\% rise 
A

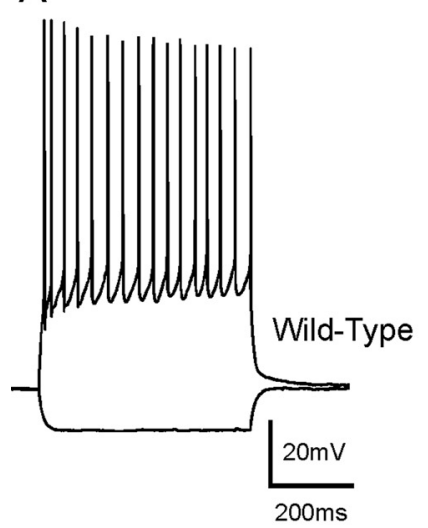

B

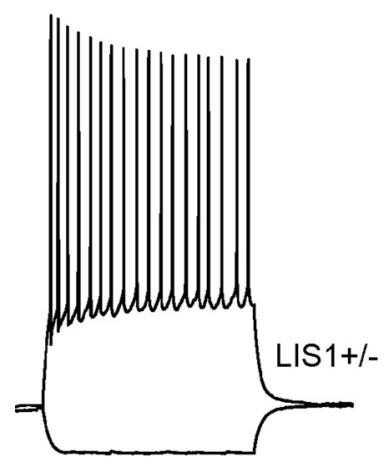

C

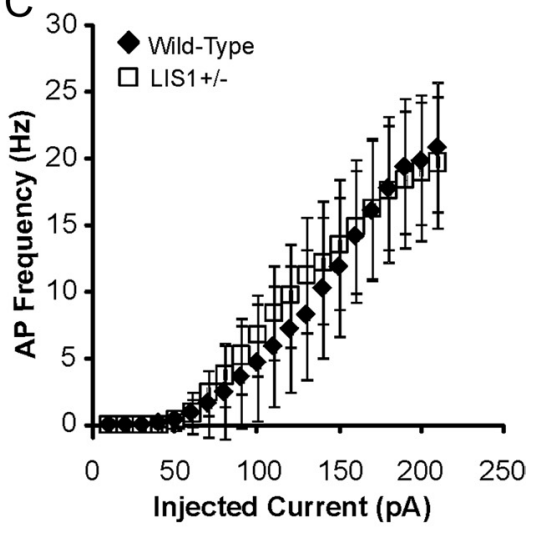

D

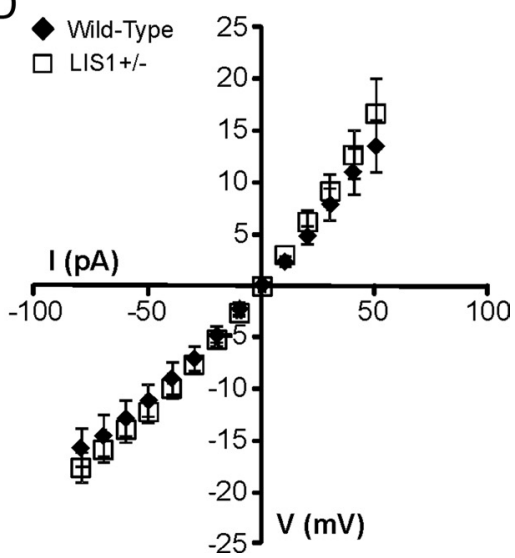

Figure 3. LIS1 deficiency does not alter intrinsic electrophysiological properties of granule cells. $A, B$, Voltage responses to hyperpolarizing $(-50 \mathrm{pA})$ and depolarizing $(+150 \mathrm{pA})$ current pulses in granule cells from a wild-type control animal $(\boldsymbol{A})$ and an LIS1 mutant $(\boldsymbol{B})$. Dentate granule cells show accommodating firing patterns. $\boldsymbol{C}$, Plot of the mean firing frequency as a function of current intensity shows no difference between groups. $\boldsymbol{D}$, Summary current-voltage plot shows that $R_{\text {input }}$ is not different between groups.

time, and decay time constant. Events characterized by a typical fast rising phase and exponential decay phase were manually detected using MiniAnalysis. For both sEPSCs and eEPSCs, the threshold for event detection currents with amplitudes greater than three times the root mean square noise level were included for analysis. Event characteristics were averaged across neurons (i.e., $n=$ neurons). For cell quantifications, cells were manually counted in three randomly selected 50- $\mu \mathrm{m}$-thick sections from the middle half of the hippocampus of each animal. Results were calculated as the average number of cells per section for each animal. Experimental groups were compared by two-tailed Student's $t$ test or by one-way ANOVA, followed by a Tukey's post hoc test. Data are expressed as mean \pm SEM, and significance was set at $p<0.05$.

\section{Results}

Granule cell layer dispersion in LIS1 mutant mice

LIS1 mutant mice display granule cell layer dispersion, aberrant neurogenesis, cognitive deficit, and spontaneous seizures (Paylor et al., 1999; Fleck et al., 2000; Wang and Baraban, 2007, 2008; Greenwood et al., 2009). To examine the effect of reduced LIS1 on excitability in a malformed DG, we crossed $L I S 1^{+/-}$mutants with POMC:EGFP transgenic reporter mice. In these animals, EGFP is expressed in a subset of adult-generated granule cells ( 1-3 weeks postmitotic) (Cowley et al., 2001; Overstreet et al.,
2004; Overstreet-Wadiche and Westbrook, 2006). We examined the brains of 11 wild-type and six LIS1 mutant mice in a series of immunohistochemical studies. Mature granule cells were identified using an antibody for NeuN or PROX1, which is expressed in granule cell nuclei (Liu et al., 2000; Pleasure et al., 2000; Elliott et al., 2001; Szabadics et al., 2010) but absent or barely detectable in POMC:EGFP-labeled neurons (Overstreet et al., 2004; Overstreet-Wadiche and Westbrook, 2006). As expected, granule cells formed a discrete, compact cell layer in wild-type control mice (Fig. 1 $A-C$ ). EGFP-labeled cells in the DG of wild-type animals were normally located in or near the granule cell layer (Fig. $1 A-C$ ), with only very few EGFP cells in the hilus or molecular layer. These cells displayed immature neuronal morphology, with short dendrites that projected through the granule cell layer but not the molecular layer, consistent with previous reports (Overstreet et al., 2004; Overstreet-Wadiche and Westbrook, 2006; Overstreet-Wadiche et al., 2006).

In LIS1 mutants, granule cell somata were heterotopic and "loosely packed," with numerous granule cell bodies displaced into the molecular layer or hilus (Fig. $1 D-F$ ). It was often difficult to clearly distinguish the borders of these regions with a defined, "normotopic" granule cell layer. Immunostaining for NeuN further confirmed the disorganization of hippocampal and granule cell layers in LIS1 mutants (Fig. 1D). Similarly, EGFPlabeled cells were often abnormally positioned in the molecular layer, hilus, and granule cell layer of 8-week-old LIS1 mutants (Fig. $1 D-F)$. In wild-type and LIS1 mutant mice, nearly all EGFP-labeled cells were immunoreactive for the immature neuronal marker DCX (98.5\% in wild-type and 97.9\% in LIS1 mutants; Fig. 2); not all DCX-positive cells contained EGFP, consistent with a previous report (Overstreet-Wadiche and Westbrook, 2006). We found a significant decrease in the number of EGFP-labeled cells per section in LIS1 mutant mice (wildtype, $118.6 \pm 12.6$ cells per section; $L I S 1^{+/-}, 77.5 \pm 9.6$ cells per section; $p<0.05$, two-tailed $t$ test). A comparable decrease in the total number of DCX-positive cells was observed (wild-type, $188.2 \pm 14.2$ cells per section; $L I S 1^{+/-}, 104.8 \pm 11.0$ cells per section; $p<0.001$, two-tailed $t$ test). These results confirm and extend previous descriptions of the dispersion of mature granule cells and neuronal progenitors in LIS1 mutant mice (Wang and Baraban, 2007, 2008).

Granule cell axons (i.e., mossy fibers) normally project to stratum lucidum of area CA3. Mossy fiber inputs onto CA3 pyramidal cells in LIS1 mutants appear to be functional and maintain relatively normal axonal termination patterns, but they possess a lower dynamic range of field EPSP facilitation (Fleck et al., 2000; Wang and Baraban, 2008). This might be explained by incorrect axonal targeting or fewer numbers of adult-born granule cells in LIS1 mutants (Mori-Kawakami et al., 2003; Wang and Baraban, 

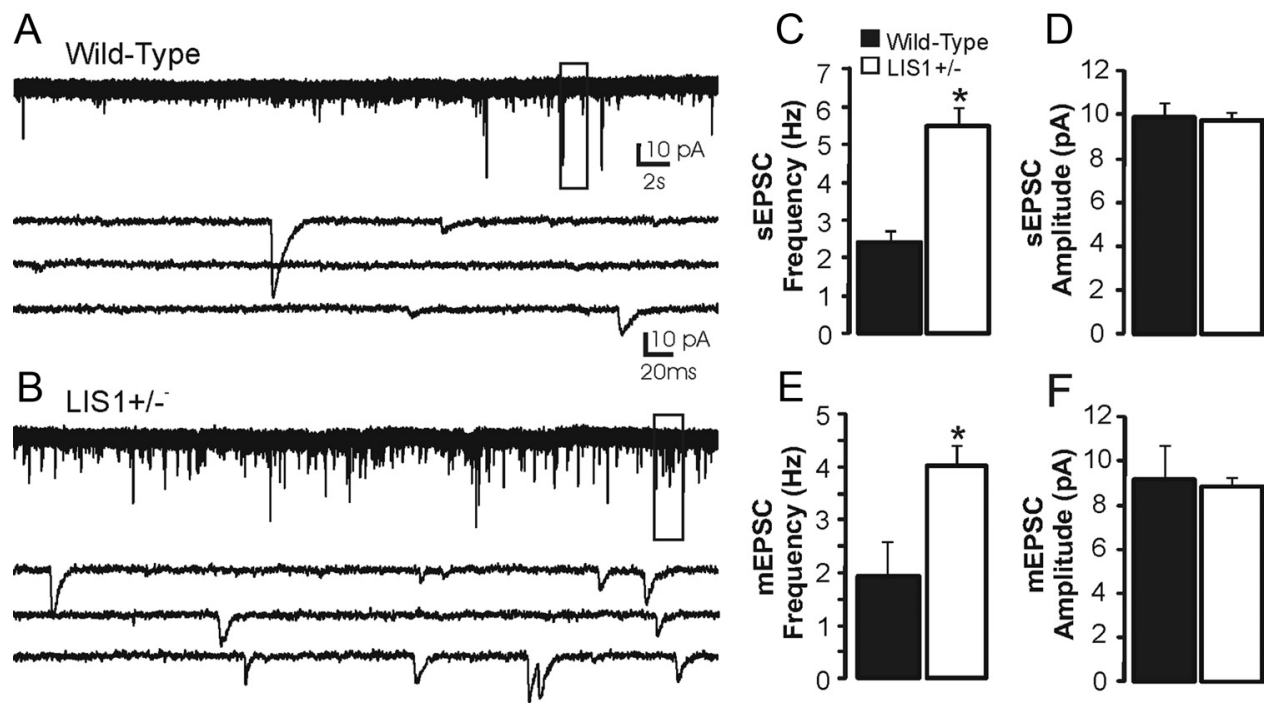

Figure 4. Excitatory synaptic input to granule cells is increased in LIS1 mutants. $A, B$, Example whole-cell voltage-clamp recording of sEPSCs from granule cells in slices from a wild-type control $(\boldsymbol{A})$ and an LIS1 mutant $(\boldsymbol{B})$. Boxes indicate the region of each trace that is expanded below. $\boldsymbol{C}$, Average sEPSC frequency for cells in each group. $\boldsymbol{D}$, Average sEPSC amplitude for cells in each group. $\boldsymbol{E}$, Average mEPSC frequency for cells in each group. $\boldsymbol{F}$, Average mEPSC amplitude for cells in each group. Significance indicated by asterisk.

2007), because immature granule cells increase excitatory synaptic facilitation at mossy fiber-CA3 synapses. Therefore, we examined axonal projections of EGFP-labeled mossy fibers using confocal microscopy (Fig. 1). Consistent with previous reports (Overstreet-Wadiche et al., 2006), labeled axons appeared relatively compact and projected to stratum lucidum of CA3 in wildtype control mice. In LIS1 mutants, EGFP axon trajectories were similar to wild-type littermate controls and did not extend beyond the CA3 border to other subfields, and mossy fiber axons were never found traversing the granule cell layer into the inner molecular layer of the DG.

\section{Intrinsic excitability of mature granule cells}

The intrinsic electrophysiological properties of dentate granule cells in epilepsy models are typically unchanged from controls (Scharfman et al., 2000; Kobayashi and Buckmaster, 2003). However, changes in membrane excitability of neurons have consistently been described in neuronal migration disorders (Castro et al., 2001; Trotter et al., 2006; George and Jacobs, 2011; Zhou and Roper, 2011) and could contribute to abnormal network excitability. Therefore, we first obtained somatic whole-cell current-clamp recordings from granule cells of wild-type controls $(n=14)$ and age-matched LIS1 mutants $(n=14)$ to compare passive membrane and intrinsic firing properties. As expected, granule cells displayed hyperpolarized resting membrane potentials (wild-type, $-72 \pm 0.96 \mathrm{mV}$; LIS1, $-74.5 \pm 1.53 \mathrm{mV} ; p=0.33$, two-tailed $t$ test), relatively large input resistances (wild-type, $249.8 \pm 33.4 \mathrm{M} \Omega$; LIS1, $284 \pm$ 22.6 M $\Omega ; p=0.4$, two-tailed $t$ test), and fast membrane time constants (wild-type, $31.7 \pm 3.7 \mathrm{~ms}$; LIS1, $32.2 \pm 2.1 \mathrm{~ms} ; p=0.9$, two-tailed $t$ test); significant differences were not detected among the experimental groups. Granule cells also displayed accommodating firing patterns (ratio of interspike interval between the last two action potentials in the train compared with the first two at two times spike threshold: wild-type, $1.9 \pm 0.3$; LIS1, $2.6 \pm 0.7$; $p=0.35$ ), and depolarizing current pulses evoked trains of action potentials that typically reached a maximum firing frequency of 15-25 Hz (Fig. 3). These are common features of dentate granule cells (Staley et al., 1992; Szabadics et al., 2010). Next, input- output properties were analyzed by plotting firing frequency versus injected current (Fig. 3C). We did not detect a significant difference between experimental groups $(p=0.49$, two-tailed $t$ test). These results suggest that intrinsic electrophysiological properties of granule cells are not different between LIS1 mutants and wild-type controls, as reported previously for CA1 pyramidal neurons (Greenwood et al., 2009).

\section{Increased excitatory synaptic input to granule cells in LIS1 mutant mice}

Acquired epilepsy models are often associated with an increase in excitatory synaptic input to granule cells (Wuarin and Dudek, 2001; Overstreet-Wadiche et al., 2006; Hunt et al., 2010). Although previous Golgi staining demonstrated that most granule cells in LIS1 mutant mice appear morphologically similar to controls, subpopulations of neurons were described as having enlarged somata and abnormal dendritic morphology (Fleck et al., 2000). This might be consistent with an increase in excitability. To date, the functional characterization of granule cells in neuronal migration disorders have been limited (Fleck et al., 2000; Wenzel et al., 2001; Patel et al., 2004; Patrylo and Willingham, 2007), and little systematic effort has been made to examine synaptic dysfunction in the DG of malformationassociated epilepsies.

To address whether there are changes in excitatory input to granule cells in LIS1 mutants, we obtained whole-cell voltageclamp recordings of sEPSCs from granule cells at a holding potential of $-70 \mathrm{mV}$. At this potential, outward events were not typically observed, and inward currents were blocked by application of $1 \mathrm{~mm}$ kynurenic acid $(n=3)$, indicating that these currents were mediated by glutamate receptors. Representative recordings for each group are shown in Figure 4, $A$ and $B$. Mean sEPSC frequency was significantly higher in granule cells of LIS1 mutants versus controls (wild-type, $2.39 \pm 0.32 \mathrm{~Hz}, n=19$; LIS1, $5.47 \pm 0.51 \mathrm{~Hz}, n=20 ; p<0.001$, two-tailed $t$ test). We did not detect a difference in mean sEPSC amplitude (wild-type, $9.9 \pm$ $0.66 \mathrm{pA}$; LIS1, $9.75 \pm 0.41 \mathrm{pA} ; p=0.79$, two-tailed $t$ test). EPSC event kinetics was comparable with previous reports (Keller et al., 1991; Staley and Mody, 1992; Hunt et al., 2010), and a difference 


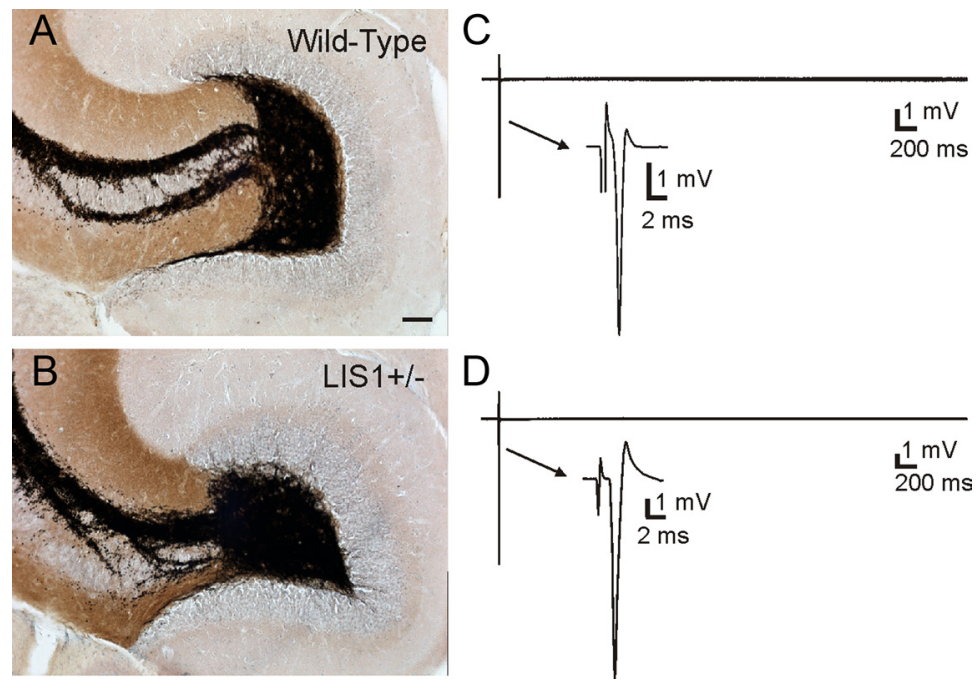

Figure 5. LIS1 mutant mice do not display abnormal mossy fiber reorganization. $\boldsymbol{A}$, Timm's- and Nissl-stained section from a wild-type animal. $\boldsymbol{B}$, Timm's- and Niss-stained section from an LIS1 mutant mouse. Note the absence of mossy fiber sprouting into the inner molecular layer. $C$, Hilar stimulation in a wild-type animal evoked a single population spike in $\mathrm{Mg}^{2+}$-free ACSF containing $30 \mu \mathrm{M}$ BMI. D, Hilar stimulation in LIS1 mutants also evoked a single population spike in $\mathrm{Mg}^{2+}$-free ACSF containing $30 \mu \mathrm{M}$ BMI. Arrows in $\mathbf{C}$ and $\boldsymbol{D}$ indicate expanded portion of the 5-s-long trace to show the population spike. Scale bar, $100 \mu \mathrm{m}$.

was not detected in the mean $10-90 \%$ rise time (wild-type, $1.25 \pm 0.06 \mathrm{~ms}$; LIS1, $1.2 \pm 0.04 \mathrm{~ms} ; p=0.27$ ) or decay time constant (wild-type, $3.56 \pm 0.22 \mathrm{~ms}$; LIS1, $3.33 \pm 0.15 \mathrm{~ms} ; p=$ $0.35)$.

Greater sEPSC frequency in granule cells of LIS1 mutants could be attributable to more excitatory synapses onto granule cells, altered probability of neurotransmitter release, or enhanced activity of presynaptic glutamatergic neurons (i.e., entorhinal inputs). To examine these possibilities, we first analyzed mEPSC characteristics in the presence of $2 \mu \mathrm{M}$ TTX (Fig. 4E,F). Similar to spontaneous events and consistent with a hyperexcitable state, mEPSC frequency was greater in LIS1 mutants versus wild-type controls (wild-type, $1.93 \pm 0.66 \mathrm{~Hz}, n=7$; LIS1, $4.02 \pm 0.36 \mathrm{~Hz}$, $n=11 ; p<0.01$, two-tailed $t$ test). We did not detect a difference in mean mEPSC amplitude between groups (wild-type, $9.24 \pm$ 1.49 pA; LIS1, $8.9 \pm 0.39 \mathrm{pA} ; p=0.74$, two-tailed $t$ test), implying a presynaptic change in excitation in LIS1 mutant mice. We also did not detect a difference in $10-90 \%$ rise time (wild-type, $1.38 \pm$ $0.15 \mathrm{~ms}$; LIS1, $1.21 \pm 0.04 \mathrm{~ms} ; p=0.15$ ) or decay time constant (wild-type, $4.06 \pm 0.5 \mathrm{~ms} ; 3.86 \pm 0.28 \mathrm{~ms} ; p=0.69$ ). These findings extend and confirm previous observations from dysplastic CA1 pyramidal neurons in these mutants (Greenwood et al., 2009) and suggest a direct role for LIS1 in selectively mediating excitatory synaptic transmission; similar effects on mIPSC frequency were not observed (Jones and Baraban, 2007).

\section{LIS1 mutant mice do not develop mossy fiber sprouting}

Mossy fiber sprouting into the inner molecular layer of the DG is a common feature of temporal lobe epilepsy and might contribute to the increase in excitatory synaptic input to granule cells of LIS1 mutants. Previous studies have shown a positive relationship between EPSC frequency in granule cells and the density of Timm's staining in the inner molecular layer of acquired epilepsy models (Wuarin and Dudek, 2001; Hunt et al., 2010). Therefore, we performed Timm's staining to examine mossy fiber organization in wild-type control $(n=4)$ and LIS1 mutant $(n=4)$ mice. As expected, mossy fibers were confined to the hilus and stratum lucidum of area CA3 in wild-type animals (Fig. 5A). In LIS1 mutants, mossy fiber trajectories were similar to wild-type littermate controls. However, separation of the suprapyramidal and infrapyramidal bundles in area CA3 was evident in all LIS1 mutant mice. Abnormal mossy fiber sprouting into the inner molecular layer was not present in any mouse examined (Fig. 5B).

To verify the absence of functional synaptic reorganization attributable to mossy fiber sprouting, we also examined extracellular field responses in the granule cell layer to electrical stimulations applied to the hilus. For these experiments, hippocampal slices were surgically isolated from afferent input and perfused with $\mathrm{Mg}^{2+}$-free ACSF containing $30 \mu \mathrm{M}$ BMI to block $\mathrm{GABA}_{\mathrm{A}}$ receptor-mediated inhibition and unmask NMDA-receptor mediated excitatory synapses at resting membrane potential (Hunt et al., 2009, 2010). Electrical stimulation consistently evoked a single population spike in all hippocampal slices from wild-type control $(n=3)$ and LIS1 mutant $(n=3)$ mice (Fig. $5 C, D$ ), and the secondary population activity that typically accompanies recurrent granule cell circuits in acquired epilepsy was never observed. Together, these findings indicate that the increase in EPSC frequencies in LIS1 mutants is not attributable to aberrant mossy fiber reorganization in the DG.

\section{Altered short-term synaptic plasticity in LIS1 mutant mice}

More frequent mEPSCs onto granule cells could be attributable to enhanced glutamatergic synaptic efficacy or a change in glutamate release probability as suggested previously at the Schaffer collateral-CA1 synapse (Greenwood et al., 2009). Therefore, we examined granule cell responses to paired-pulse stimulation of the perforant pathway, a commonly used measure of presynaptic short-term plasticity that has an inverse relationship to overall release probability (Millar et al., 2002; Xu-Friedman and Regehr, 2004). A stimulating electrode was placed in subiculum near the fissure between the upper blade of the granule cell layer and subiculum, and paired stimuli were applied to the perforant pathway (40 ms interval, two times the threshold for event detection, $100 \mu \mathrm{s}, 0.1 \mathrm{~Hz}$ ). Recordings were obtained at $-70 \mathrm{mV}$ in the presence of $30 \mu \mathrm{M}$ BMI. Paired-pulse facilitation of the EPSC amplitude was observed in granule cells of wild-type animals (PPR, $1.53 \pm 0.13$; Fig. 6A,B), as expected. These PPRs were comparable with previous reports (Szabadics et al., 2010). However, PPRs in granule cells of LIS1 mutants were significantly lower compared with controls (LIS1 PPR, $1.07 \pm 0.08 ; p<0.001$, two-tailed $t$ test), with 7 of 15 cells displaying paired-pulse depression.

Our paired-pulse results indicate that there is an increase in release probability of entorhinal glutamatergic input to granule cells of LIS1 mutants. To verify this finding, stimulus intensity was adjusted to produce an eEPSC at threshold, which was defined as the minimal intensity necessary to evoke a response at a holding potential of $-70 \mathrm{mV}$ ( single stimulation, $100 \mu \mathrm{s}, 0.1 \mathrm{~Hz}$ ). Twenty consecutive responses were measured, and the mean EPSC synaptic transmission rate was calculated as one minus the synaptic failure rate. Representative recordings are shown in Figure 6C-E. The mean amplitude, excluding failures, of eEPSCs at thresh- 
old was not statistically different between wild-type and LIS1 mutants (wild-type, $13.7 \pm 1.8 \mathrm{pA} ; \mathrm{LIS} 1,12.5 \pm 1.7 \mathrm{pA} ; p=0.59$, two-tailed $t$ test) (Fig. 6D). Threshold stimulations resulted in frequent response failures in granule cells of wild-type animals (transmission rate $=0.48 \pm 0.04 ; n=13$ ). The mean EPSC synaptic transmission rate was $0.7 \pm 0.03$ in granule cells from LIS1 mutants $(n=11)$. Although $\sim 50 \%$ eEPSC transmission failure observed in controls is comparable with previous reports (Min et al., 1998), response failures were less frequent in LIS1 mutants versus wild-type animals $(p<0.001$, two-tailed $t$ test). Together, these findings reveal that release probability at the perforant pathway-granule cell synapse is enhanced in LIS1 mutant mice.

If there is an increase in the number of functional excitatory synaptic contacts onto granule cells in LIS1 mutants, an increase in the slope of the input-output curve for perforant pathway-evoked EPSC amplitudes might be expected (Hsia et al., 1999; Li and Prince, 2002). To examine this possibility, we obtained wholecell voltage-clamp recordings in granule cells at $-70 \mathrm{mV}$ in the presence of $30 \mu \mathrm{M}$ $\mathrm{BMI}$, and the threshold for minimal perforant pathway-evoked responses was found as described above. Input was then normalized to the threshold response by increasing stimulus strength in multiples of threshold (T, 2T, 3T, 5T, 10T, 15T). This approach assumes that eEPSC amplitudes summate linearly with the number of synapses and has been used previously to estimate the number of functional synapses in slices (Hsia et al., 1999; Li and Prince, 2002). Input-output responses were analyzed by plotting eEPSC amplitude versus normalized stimulus unit (Fig. 6F,G). Using this approach, we did not detect a significant difference between groups ( $p=0.66$, two-tailed $t$ test $)$.

\section{Enhanced functional integration of molecular layer-ectopic newborn granule cells}

Aberrant neurogenesis in the DG might

promote seizure generation (Greenwood et al., 2009) or disrupt hippocampal-dependent learning (Paylor et al., 1999) in LIS1 mutants. Local network activity is one of the most widely characterized modulators of granule cell development in the adult brain. Conditions of heightened excitability in DG are generally believed to accelerate the proliferation, maturation, and integration of adult-born granule cells (Overstreet-Wadiche et al., 2006; Piatti et al., 2011), but synaptic connections to granule cells born into a malformed DG have not been investigated. Therefore, we examined whether the functional integration or maturation of EGFP-labeled newly born granule cells was altered in heterozygous LIS1 mutant mice.

A
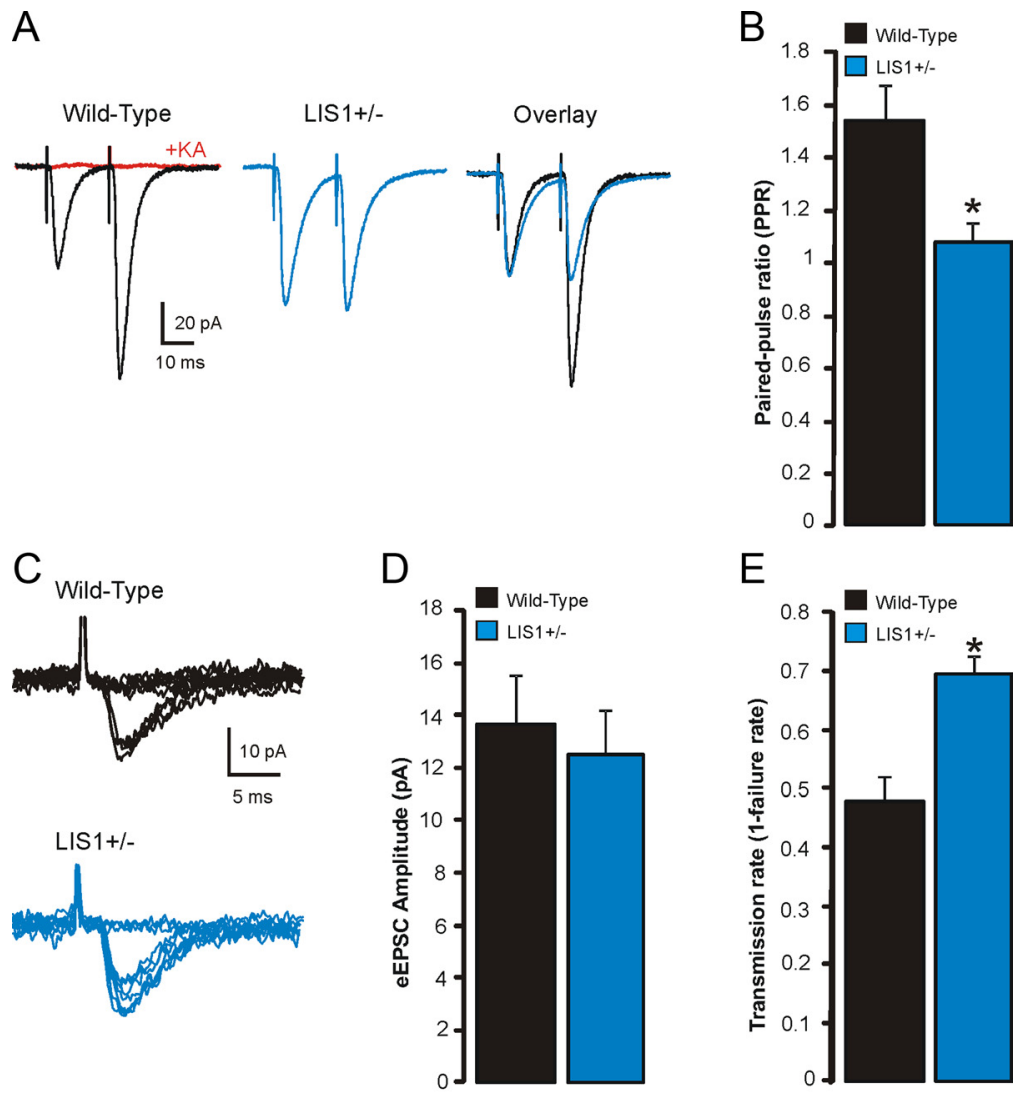

$\mathrm{E}$
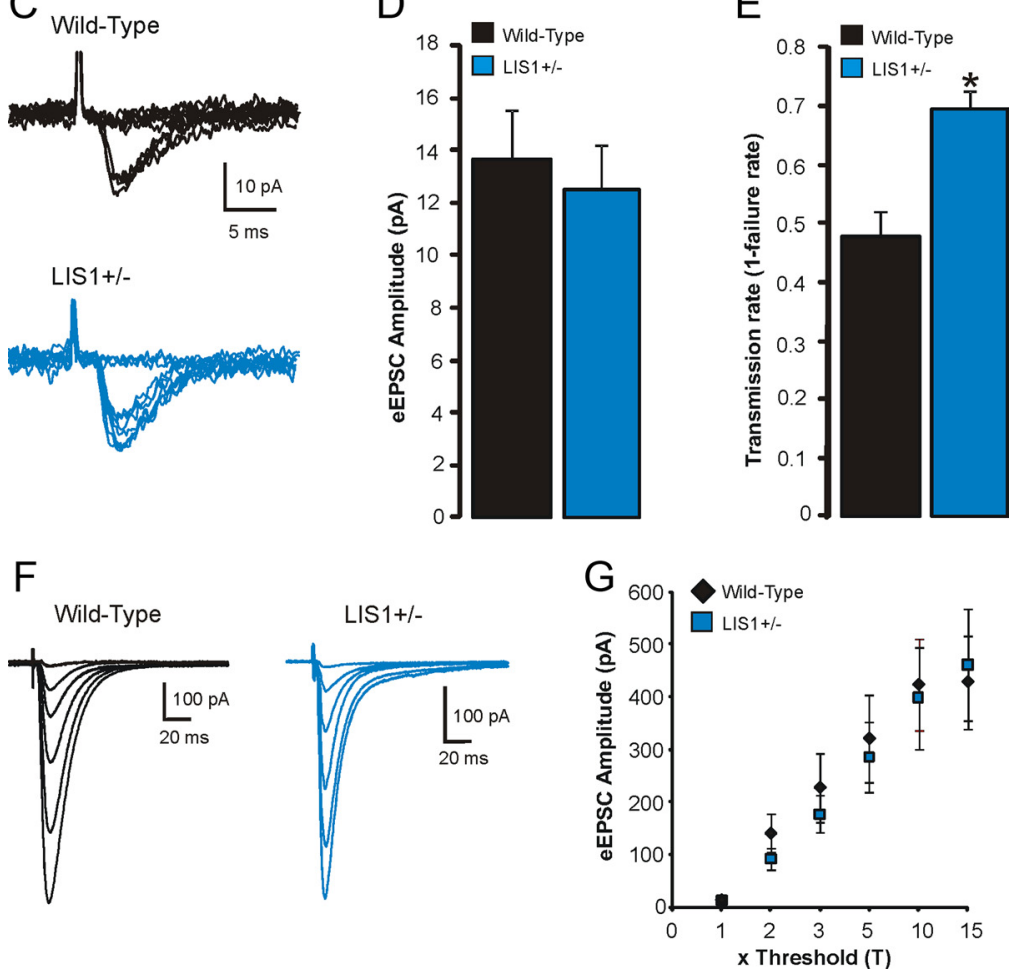

Figure 6. Altered short-term synaptic plasticity in LIS1 mutants. A, Pairs of perforant pathway-evoked EPSCs from granule cells in slices from a wild-type control (black) and an LIS1 mutant (blue). The pairing interval was $40 \mathrm{~ms}$, and each trace represents the average response of 10 consecutive trials. Overlay shows superimposed eEPSCs normalized to the first event. The application of 1 mm kynurenic acid (KA) completely blocked evoked responses (red). $\boldsymbol{B}$, Average paired-pulse responses for each group. $\boldsymbol{C}$, Example Ten consecutive responses are shown for each experimental group. D. Average minimally evoked EPSC amplitudes for each experimental group. $\boldsymbol{E}$, Average EPSC transmission rate for each group. $\boldsymbol{F}$, EPSC responses to increasing perforant pathway stimulations normalized to threshold in granule cells from wild types (black) and LIS1 mutants (blue). G, Plot of the mean EPSC amplitude as a function of normalized current intensity shows no differences between groups. Significance indicated by asterisk.

Whole-cell voltage-clamp recordings were obtained from EGFP-labeled cells in the DG at $-70 \mathrm{mV}$. EPSCs were not detected in any of the EGFP-labeled granule cells from control animals ( $n=0$ of 25 cells) (Fig. 7A). All cells were located in the granule cell layer, and this finding is consistent with previous reports that EGFP-labeled granule cells normally do not receive glutamatergic synaptic input (Overstreet-Wadiche et al., 2006). In LIS1 mutants, we obtained recordings from EGFP-labeled granule cells located in the hilus $(n=8)$, granule cell layer $(n=$ $17)$, and molecular layer $(n=9)$. sEPSCs were only detected in labeled neurons with cell bodies located in the molecular layer ( $n=5$ of 9 cells; $56 \%$ ). EGFP-labeled cells in the hilus or granule 

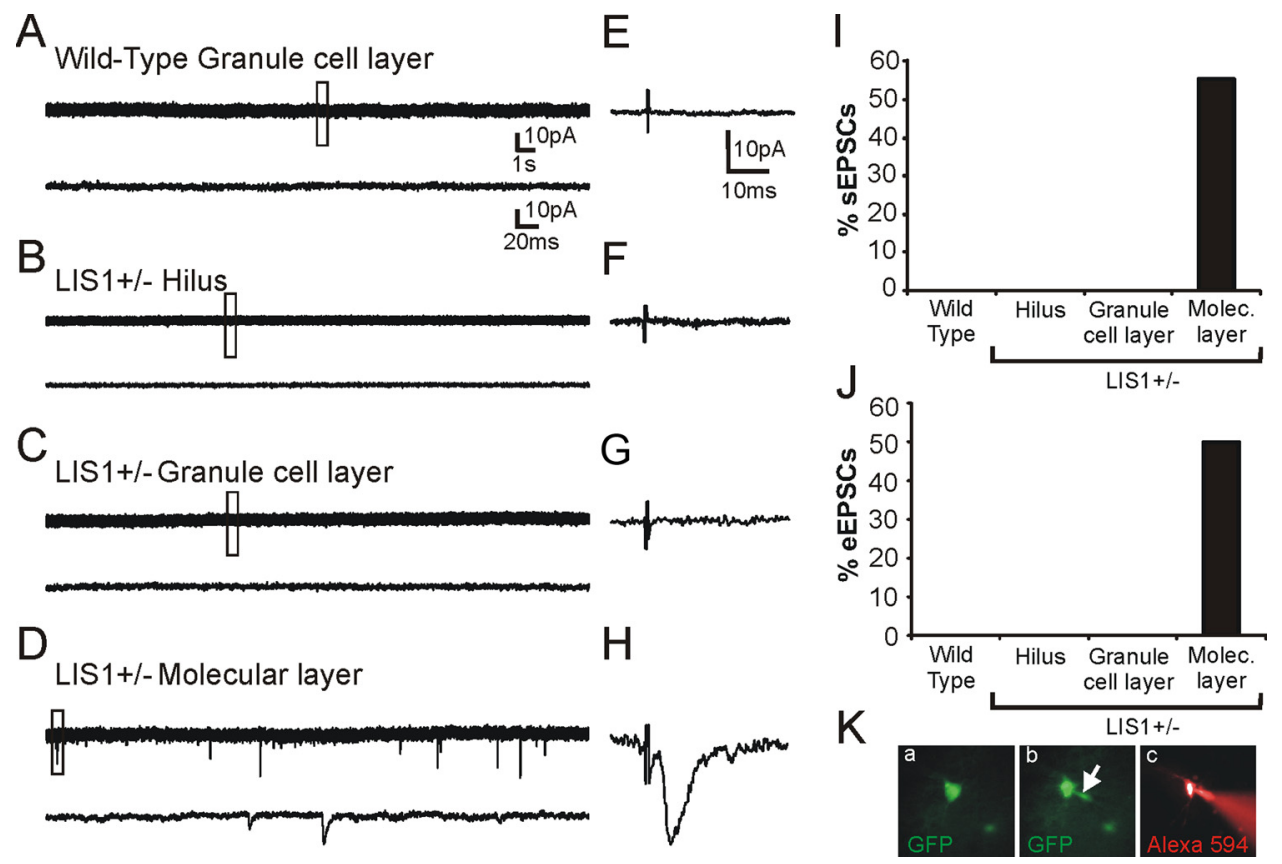

Figure 7. Newly born granule cells ectopically positioned in the molecular layer of heterozygous LIS1 mutants receive excitatory synaptic input. $\boldsymbol{A}-\boldsymbol{D}$, Example whole-cell voltage-clamp recordings of sEPSCs from EGFP-labeled granule cells located in the granule cell layer of a wild-type control $(\boldsymbol{A})$ and in EGFP cells of LIS1 mutants that were located in the hilus ( $\boldsymbol{B}$ ), granule cell layer $(\boldsymbol{C})$, and molecular layer (D). sEPSCs were only observed in EGFP cells located in the molecular layer. $\boldsymbol{E}-\boldsymbol{H}$, EPSC responses to perforant pathway stimulation from EGFP-labeled granule cells located in the granule cell layer of a wild-type control $(\boldsymbol{E})$ and EGFP cells of LIS1 mutants that were located in the hilus $(\boldsymbol{F})$, granule cell layer $(\boldsymbol{G})$, and molecular layer $(\boldsymbol{H})$. Perforant pathway-evoked EPSCs were only observed in EGFP cells located in the molecular layer. $I$, Plot of the percentage of cells in each experimental group that displayed sEPSCs. J, Plot of the percentage of cells in each experimental group that displayed eEPSCS. $\boldsymbol{K}$, Example fluorescent illumination of an Alexa Fluor 594-filled EGFP neuron visualized in a live brain slice: $\boldsymbol{a}$, EGFP-labeled neuron before recording; $\boldsymbol{b}$, EGFP-labeled neuron after membrane rupture shows EGFP into the recording pipette (arrow); and c, Alexa Flour 594 labeling of the same neuron.

A

Wild-Type Granule cell layer

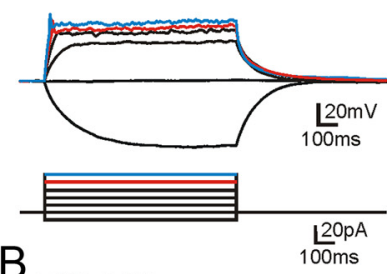

LIS1+/-Hilus
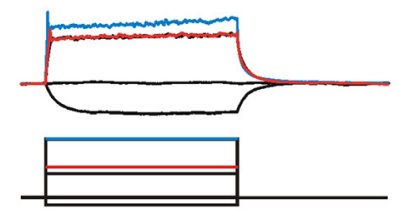

C

LIS1+/-Granule cell layer

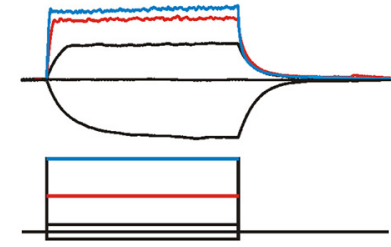

$\mathrm{D}$

LIS1+/- Molecular layer
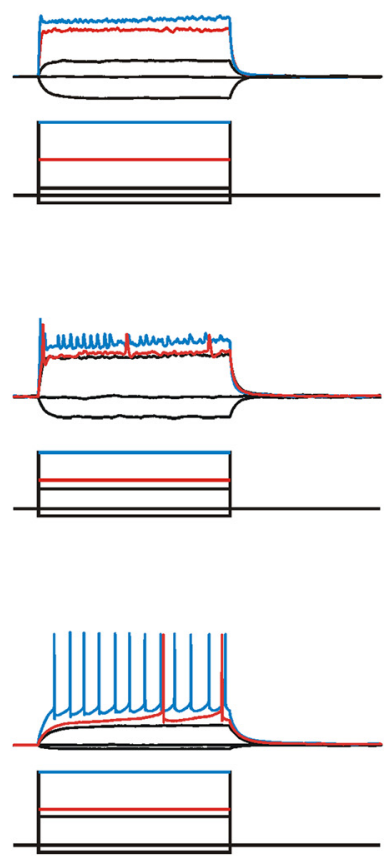

$\mathrm{E}$

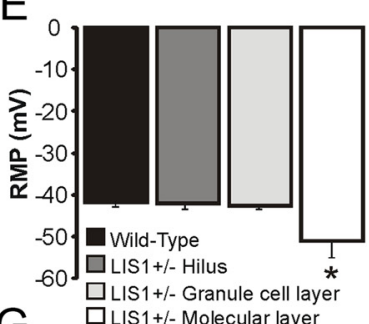

$\mathrm{G}_{100}$

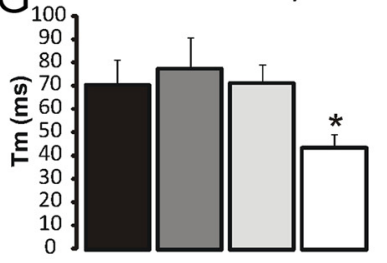

1

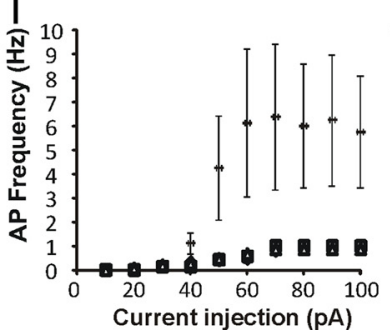

F

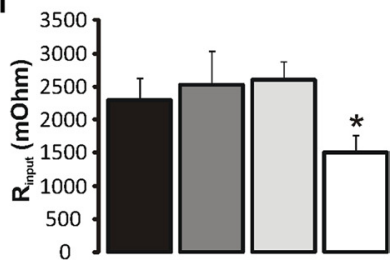

$\mathrm{H}_{5}$

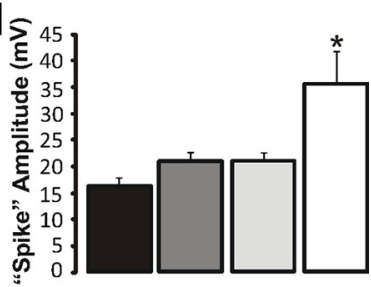

- Wild-Type

口 LIS1+/-Hilus

$\Delta$ LIS1+/-Granule cell layer

- LIS1+/- Molecular layer

Figure 8. Enhanced functional maturation of newly born granule cells in the molecular layer of LIS1 mutants. $\boldsymbol{A}-\boldsymbol{D}$, Voltage responses to hyperpolarizing and depolarizing current pulses in EGFP-labeled newborn cells in the granule cell layer of a wild-type control $(\boldsymbol{A})$ and EGFP cells of LIS1 mutants that were located in the hilus $(\boldsymbol{B})$, granule cell layer $(\boldsymbol{C})$, and molecular layer $(\boldsymbol{D})$. Three examples of newly born ML-EGCs are shown. Note the reduced input resistance $\left(R_{\text {input }}\right)$ and greater action potential firing in some molecular layer-ectopic neurons. $\boldsymbol{E}$, Mean resting membrane potential (RMP) for each group. $\boldsymbol{F}$, Mean $R_{\text {input }}$ for each group. $\boldsymbol{G}$, Mean membrane time constant (Tm) for each group. $\boldsymbol{H}$, Mean spike amplitude for each group. $\boldsymbol{I}$, Plot of the mean firing frequency as a function of current intensity shows greater action potential (AP) firing in EGFP cells of LIS1 mutants that were located in the molecular layer. Significance indicated by asterisk. 
cell layer did not receive EPSCs. The mean sEPSC characteristics for cells that received EPSCs were as follows: frequency, $0.38 \pm 0.11 \mathrm{~Hz}$; amplitude, $10.9 \pm 2.45$ pA; $10-90 \%$ rise time, $1.0 \pm 0.17 \mathrm{~ms}$; decay time constant, $2.49 \pm 0.38 \mathrm{~ms}$. Representative recordings for each group are shown in Figure $7 A-D$. To determine whether molecular layer-ectopic neurons received entorhinal input, we measured excitatory synaptic responses in EGFPlabeled newborn granule cells to stimulations applied to the perforant pathway. Recordings were performed in the presence of $30 \mu \mathrm{M}$ BMI to block $\mathrm{GABA}_{\mathrm{A}}$ receptor-mediated inhibitory events. Similar to spontaneous network events, perforant pathway-evoked EPSCs were only detected in molecular layer-ectopic neurons (wild-type, $n=0$ of 10; LIS1 hilus, $n=0$ of 5 ; LIS1 granule cell layer, $n=$ 0 of 9; and LIS1 molecular layer, $n=3$ of $6)$. Together, these results suggest that ectopic positioning within the disorganized DG influences functional integration of EGFP-labeled cells.

The presence of excitatory input to newborn molecular layer-ectopic granule cells (ML-EGCs) of LIS1 mutants might indicate enhanced functional maturity of these cells. To examine this possibility, whole-cell current-clamp recordings were obtained from EGFP granule cells of wild-type controls and LIS1 mutants. Cells were held at $-70 \mathrm{mV}$, and intrinsic electrophysiological properties were measured in response to hyperpolarizing and depolarizing current injections (10 pA steps; range, -10 to $100 \mathrm{pA}$; $1000 \mathrm{~ms}$ ). EGFP-labeled granule cells from wild-type animals $(n=16)$ were compared with granule cells of LIS1 mutants according to the anatomical location of the cell: hilus $(n=8)$, granule cell layer $(n=15)$, and molecular layer $(n=8)$. Representative recordings are shown in Figure $8 A-D$. Significant differences were detected in resting membrane potential (wild-type, $-42.13 \pm$ $0.82 \mathrm{mV}$; LIS1 hilus, $-42.3 \pm 1.4 \mathrm{mV}$; LIS1 granule cell layer, $-43.0 \pm 0.87 \mathrm{mV}$; LIS1 molecular layer, $-51.4 \pm 3.85 \mathrm{mV} ; p<$ 0.001 , one-way ANOVA), $R_{\text {input }}$ (wild-type, $2.3 \pm 0.33 \mathrm{M} \Omega$; LIS1 hilus, $2.52 \pm 0.52 \mathrm{M} \Omega$; LIS1 granule cell layer, $2.6 \pm 0.28 \mathrm{M} \Omega$; LIS1 molecular layer, $1.5 \pm 0.26 \mathrm{M} \Omega ; p<0.05$, one-way ANOVA), and $\tau_{\mathrm{m}}$ (wild-type, $70.8 \pm 10.6 \mathrm{~ms}$; LIS1 hilus, $77.8 \pm 13.52 \mathrm{~ms}$; LIS1 granule cell layer, $71.5 \pm 8.13 \mathrm{~ms}$; LIS1 molecular layer, $43.42 \pm 6.2 \mathrm{~ms} ; p<0.05$, one-way ANOVA). Tukey's post hoc analysis revealed that ML-EGCs displayed significantly different electrophysiological characteristics, with passive membrane properties approaching values expected of mature granule cells. Scale bars, $250 \mu \mathrm{m}$.
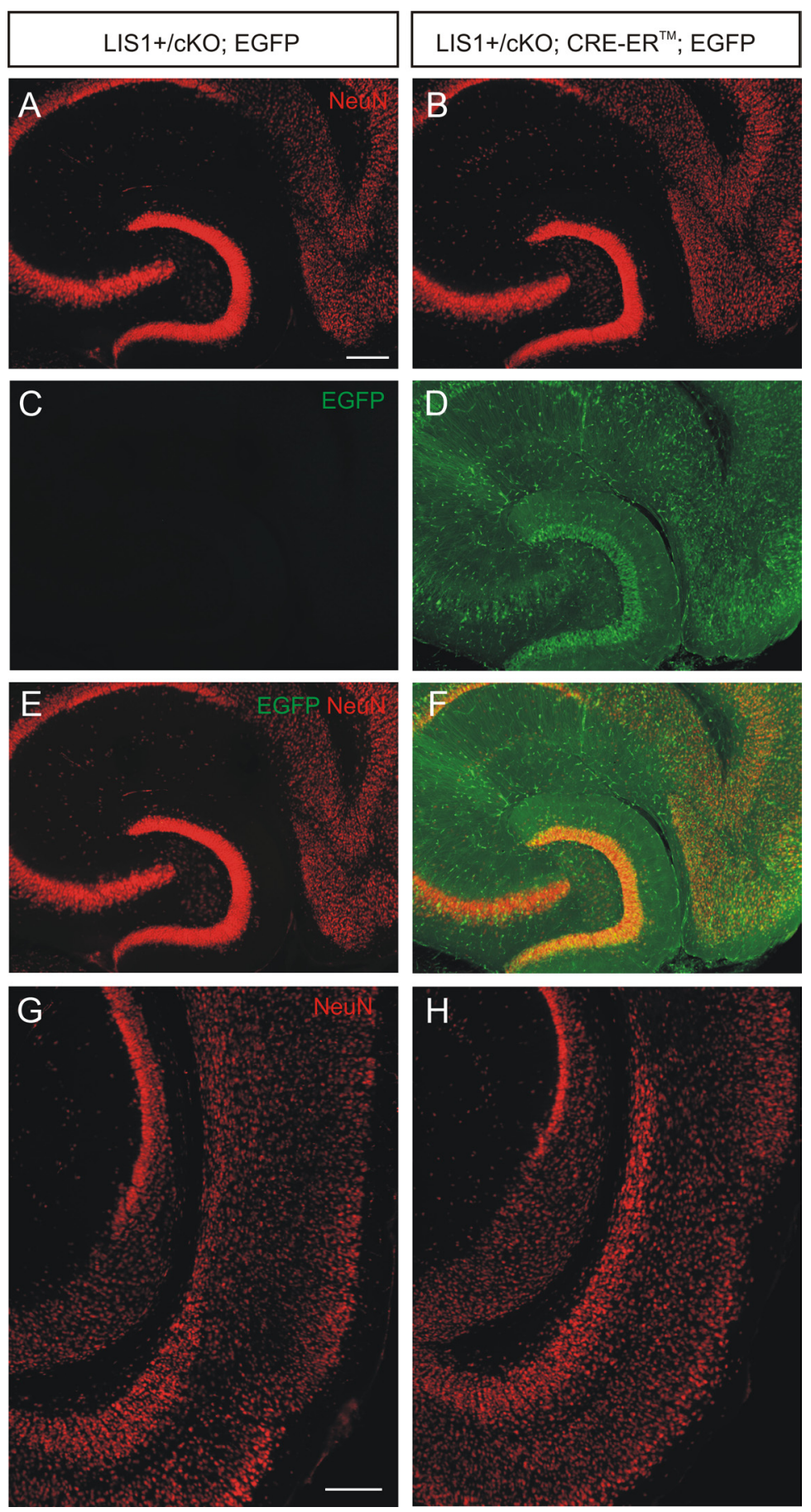

Figure 9. LIS1 deficiency in adulthood does not disrupt laminar organization in the DG. $A, C, E$, Confocal images of NeuN (red) and EGFP (green) immunostaining 6 weeks after tamoxifen administration in an $L I S 1^{+/ c K O} ; E G F P$ mouse that did not express Cre. Note the absence of EGFP immunostaining. $\mathbf{G}$, NeuN immunostaining of the entorhinal cortex in the same section from an $L I S T^{+/ C K O} ; E G F P$ control mouse. $\boldsymbol{B}, \boldsymbol{D}, \boldsymbol{F}$, NeuN (red) and EGFP (green) immunostaining 6 weeks after tamoxifen administration in an $L I S 1^{+/ C K O}$; Cre-ER; EGFP mouse. Widespread expression of EGFP indicates Cre-mediated recombination. Note the compact cell layers in this animal. $\boldsymbol{H}$, NeuN immunostaining of the entorhinal cortex in the same section from an $L I S 1^{+/ C K O}$; $C$ re-ER; EGFP mouse.

Newly born ML-EGCs of LIS1 mutants also showed more mature action potential firing versus cells located in the hilus, granule cell layer, or in wild-type controls. Depolarizing current pulses typically evoked a single, small, broad action potential in EGFP-labeled newborn granule cells of controls, consistent with previous reports (Overstreet et al., 2004; Overstreet-Wadiche and Westbrook, 2006). EGFP-labeled ML-EGCs had significantly larger 

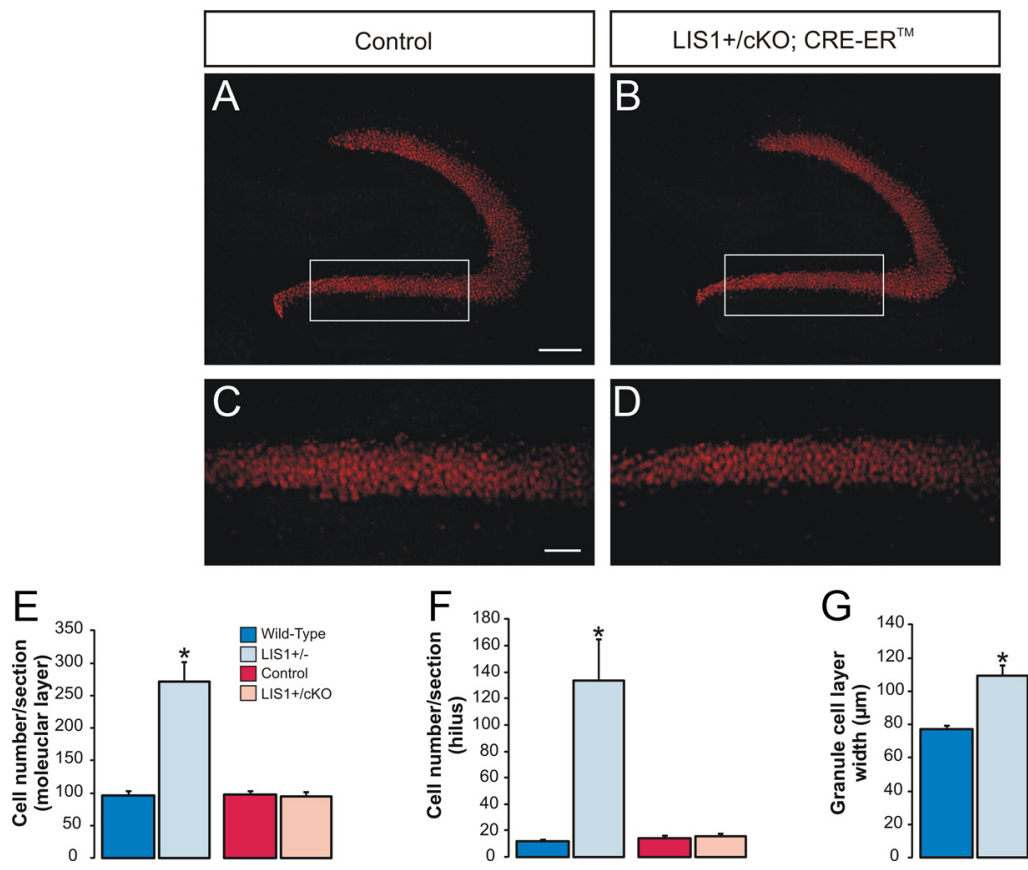

Figure 10. LIS1 deficiency in adulthood does not significantly disrupt granule cell layer organization. $A$, PROX1 immunostaining in the DG 6 weeks after tamoxifen administration in an $L / S 1^{+/ C K O}$ mouse that did not express Cre. B, PROX1 immunostaining in the DG 6 weeks after tamoxifen administration in an $\mathrm{LIS1^{+/CKO }}$; $\mathrm{Cre}-E R$; EGFP mouse. Note the compact granule cell layer in this animal. $\boldsymbol{C}, \boldsymbol{D}$, High-magnification images of the boxed regions shown $\boldsymbol{A}$ and $\boldsymbol{B}$. $\boldsymbol{E}$, Quantification of the average number of PROX1-labeled cells found in the molecular layer per section in wild-type, $L I S 1^{+/-}$mutants, tamoxifen-injected controls, and $L I S 1^{+/ C K O}$; $C \mathrm{re}$ mutant mice. $F$, Quantification of the average number of PROX1-labeled cells found in the hilus per section for each experimental group. G, Quantification of the average width of the granule cell layer for each experimental group. Significance indicated by asterisk. Note that an increase in the number of ectopically positioned granule cells and granule cell layer width were only observed in heterozygous LIS1 mutants. Scale bars: $\boldsymbol{A}, \boldsymbol{B}, 167 \mu \mathrm{m} ; \boldsymbol{C}, \boldsymbol{D}, 50 \mu \mathrm{m}$.

"spike" amplitude (wild-type, $15.1 \pm 2.2 \mathrm{mV}$; LIS1 hilus, $20.9 \pm$ $1.7 \mathrm{mV}$; LIS1 granule cell layer, $18.0 \pm 2.6 \mathrm{mV}$; LIS1 molecular layer, $35.4 \pm 6.2 \mathrm{mV} ; p<0.001$, one-way ANOVA). Input-output properties were analyzed by plotting firing frequency versus injected current (Fig. 8I). We found that there was greater action potential firing in newborn ML-EGCs $(p<0.01$, one-way ANOVA). "Repetitive firing" was only observed in ML-EGCs of LIS1 mutant mice. These findings are consistent with a selective increase in the functional maturation of EGFP-labeled granule cells found in the molecular layer of LIS1 mutants.

\section{Enhanced excitatory synaptic input to granule cells in LIS1 conditional knock-out mice}

LIS1 deficiency gives rise to both structural disorganization and enhanced excitatory synaptic transmission. However, it is unknown whether the increase in excitatory input to granule cells results from malformed networks of neurons or reduced LIS1 function in the absence of neuronal disorganization. LIS1 protein expression remains high in the adult brain (Pandey and Smith, 2011), suggesting a role in maintaining normal brain function even after development is complete. Therefore, we examined the effect of LIS1 deficiency on existing circuitry in adult mice without disorganized hippocampal architecture. To do this, we generated a heterozygous deletion of LIS1 in 6-week-old conditional mutant animals, as described previously (Hirotsune et al., 1998). Briefly, mice carrying a floxed LIS1 allele $\left(L I S 1^{+/ c K O}\right)$ were crossed with mice expressing CreER to generate $L I S 1^{+/ c K O}$; CreER mice. Littermates that were missing either the floxed LIS1 allele or CreER were used as controls and received identical tamoxifen injections. To confirm recombination after tamoxifen treatment, $L I S 1^{+/ c K O}$;

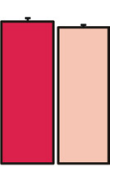

CreER mice were crossed to a CAG-CATEGFP reporter line (Kawamoto et al., 2000). Immunohistochemical analysis of EGFP revealed widespread Cre-mediated recombination in entorhinal cortex, DG, and, to a lesser extent, the hippocampus proper (Fig. 9A-F). NeuN staining confirmed the absence of gross structural changes to the principal cell layers of the hippocampus, DG, or entorhinal cortex, in contrast to $\mathrm{Lis}^{+/-}$mutant mice (Fig. 9).

PROX1 staining indicated a welldefined, compact granule cell layer in $L I S 1^{+/ c K O}$; CreER mice that was indistinguishable from controls (Fig. 10A$D)$. To examine whether significant granule cell layer dispersion occurred in conditional LIS1 mutant mice, we quantified the number of PROX1-labeled cell bodies in the hilus or molecular layer of wild types, heterozygous LIS1 mutants, tamoxifen-injected controls, and conditional LIS1 mutants (Fig. 10E,F). As expected, heterozygous LIS1 mutants had a significant increase in the number of PROX1-labeled granule cells positioned in the hilus (wild-type, $11.8 \pm 1.5$ cells per section, $n=5$ animals; $L I S 1^{+/-}$, $133.2 \pm 32.0$ cells per section, $n=5$ animals; $p<0.001$, two-tailed $t$ test) and molecular layer (wild-type, $95.4 \pm 7.9$ cells per section; $L I S 1^{+/-}, 271.4 \pm 30.1$ cells per section; $p<0.01$, two-tailed $t$ test). LIS1 mutant mice also showed a significant increase in granule cell layer width (wild-type, $76.9 \pm 2.6 \mu \mathrm{m}$; LIS1, $108.9 \pm 6.6 \mu \mathrm{m} ; p<0.01$, two-tailed $t$ test), consistent with granule cell layer dispersion in these animals (Fig. 10G). In contrast, conditional mutant mice did not show a significant change in PROX1-labeled granule cells in the hilus (control, $14.1 \pm 2.4$ cells per section, $n=7$ animals; $\mathrm{LIS1}^{+/ c K O}$; CreER ${ }^{\mathrm{TM+}-}$, $15.3 \pm 2.0$ cells per section, $n=6$ animals; $p=0.68$, two-tailed $t$ test) or molecular layer (control, $97.6 \pm 6.0$ cells per section; $L I S 1^{+/ c K O} ; \mathrm{CreER}^{T M+/-}, 93.7 \pm 7.3$ cells per section; $p=0.72$, two-tailed $t$ test). We also did not detect a change in granule cell layer width between groups (control, $85.0 \pm 1.7 \mu \mathrm{m} ;$ LIS1 $^{+/ c K O} ;$ CreER $^{T M+/-}$, $81.3 \pm 2.1 \mu \mathrm{m} ; p=$ 0.21 , two-tailed $t$ test). These findings suggest that LIS1 haploinsufficiency in adulthood does not produce gross changes in the anatomical organization of hippocampus. However, we cannot rule out the possibility that there are subtle changes in granule cell organization attributable to aberrant neurogenesis after conditional LIS1 deletion.

To examine the functional effect of conditional LIS1 reduction in adult neurons, whole-cell voltage-clamp recordings were obtained from granule cells at a holding potential of $-70 \mathrm{mV}$ (Fig. 11A-F). Representative recordings for each group are shown in Figure 9, $A$ and $B$. The mean sEPSC frequency was significantly higher in granule cells of $L I S 1^{+/ c K O}$; $\mathrm{CreER}^{T M+/-}$ mice versus controls (control, $1.8 \pm 0.22 \mathrm{~Hz}, n=11 ; L I S 1^{+/ c K O}$; $\mathrm{CreER}^{T M+/-}, 3.61 \pm 0.5 \mathrm{~Hz}, n=12 ; p<0.001$, two-tailed $t$ test). We did not detect a difference in mean sEPSC amplitude (control, $9.72 \pm 0.65 \mathrm{pA} ;$ LIS1 $^{+/ c K O}$; CreER, $10.87 \pm 1.12 \mathrm{pA} ; p=0.3$, two-tailed $t$ test), $10-90 \%$ rise time (control, $1.29 \pm 0.08 \mathrm{~ms}$; 

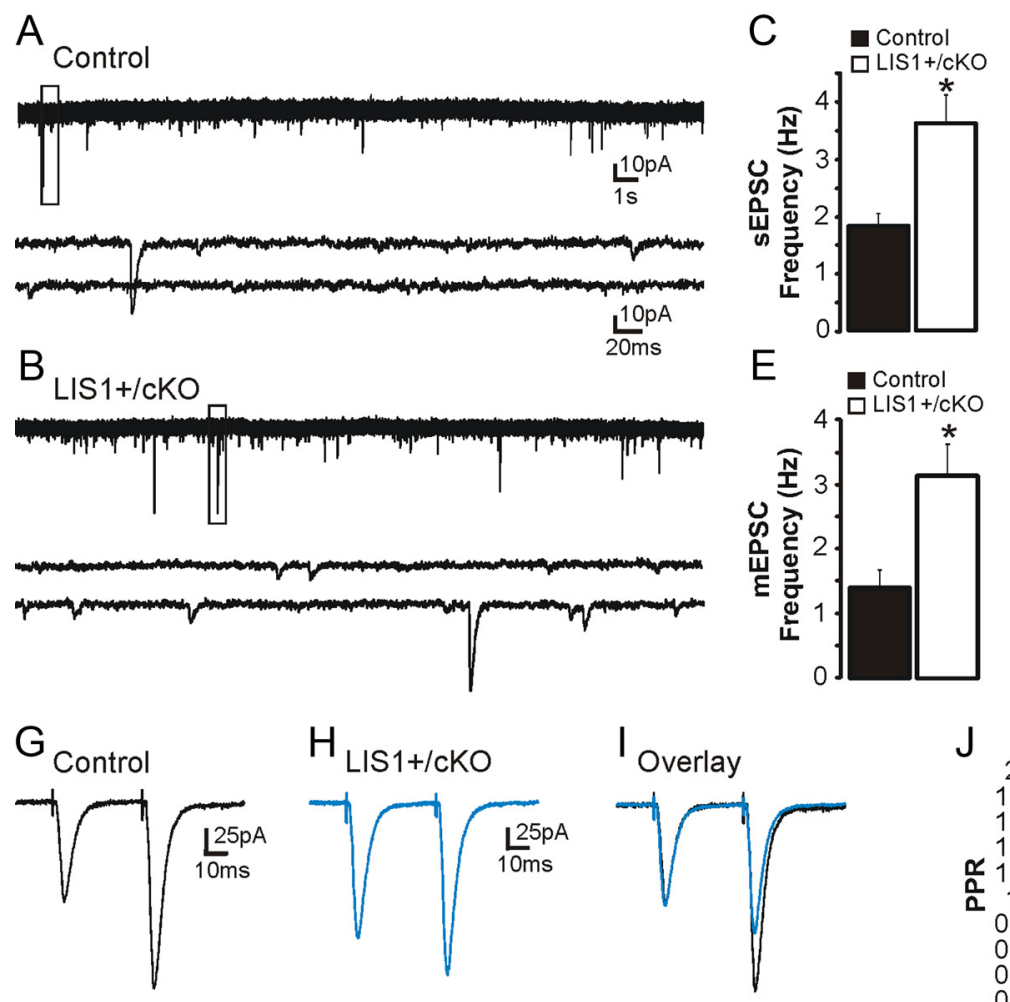

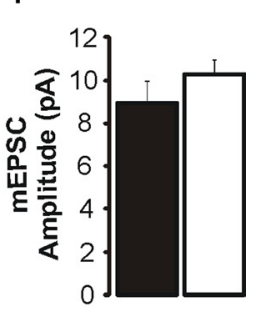

D

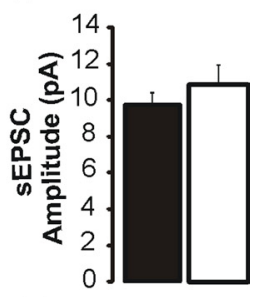

F

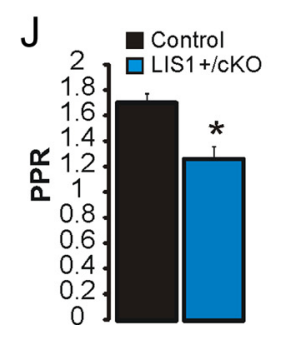

Figure 11. Excitatory synaptic input to granule cells is increased after LIS1 reduction in adulthood. $\boldsymbol{A}, \boldsymbol{B}$, Example whole-cell voltage-clamp recordings of sEPSCs obtained from granule cells in slices from a tamoxifen-injected control ( $\boldsymbol{A})$ and a conditional LIS1 mutant $(\boldsymbol{B})$. Boxes indicate the region of each trace that is expanded below. $\boldsymbol{C}$, Average sEPSC frequency for cells in each group. $\boldsymbol{D}$, Average sEPSC amplitude for cells in each group. $\boldsymbol{E}$, Average mEPSC frequency for cells in each group. $\boldsymbol{F}$, Average mEPSC amplitude for cells in each group. $\mathbf{G}-\boldsymbol{I}$, Pairs of perforant pathway-evoked EPSCs obtained from granule cells in slices from a tamoxifen-injected control $(\boldsymbol{G})$ and a conditional LIS1 mutant $(\boldsymbol{H})$. The pairing interval was 40 ms, and each trace represents the average response of 10 consecutive trials. I, Overlay shows superimposed responses to perforant pathway stimulation normalized to the first eEPSC. J, Mean paired-pulse responses for each group. Significance indicated by asterisk.

LIS1 ${ }^{+/ c K O} ;$ CreER, $\left.1.31 \pm 0.09 \mathrm{~ms} ; p=0.83\right)$, or decay time constant (control, $3.46 \pm 0.31 \mathrm{~ms}$ : LIS1 ${ }^{+/ c K O}$; CreER, $2.84 \pm 0.25 \mathrm{~ms}$, $p=0.1)$.

Similar to spontaneous events, mEPSC frequency was also greater in $L I S 1^{+/ c K O}$; CreER mice versus controls (control, $1.4 \pm$ $0.28 \mathrm{~Hz}, n=10 ; \mathrm{LIS1}^{+/ c K O}$; CreER, $3.14 \pm 0.49 \mathrm{~Hz}, n=13 ; p<$ 0.01 , two-tailed $t$ test). We did not detect a difference in mean mEPSC amplitude between groups (control, $8.9 \pm 1.03 \mathrm{pA}$; LIS1 ${ }^{+/ c K O}$; CreER, $10.27 \pm 0.7 \mathrm{pA} ; p=0.13$, two-tailed $t$ test), $10-90 \%$ rise time (control, $1.38 \pm 0.15 \mathrm{~ms}$; LIS1 ${ }^{+/ c K O}$; CreER, $1.26 \pm 0.08 \mathrm{~ms} ; p=0.32$ ), or decay time constant (control, $3.45 \pm 0.42 \mathrm{~ms} ;$ LIS1 $^{+/ c K O} ;$ CreER, $\left.2.81 \pm 0.24 \mathrm{~ms} ; p=0.1\right)$.

Finally, PPRs were examined as described above (Fig. 11G-J). Similar to LIS1 mutants, granule cells of $L I S 1^{+/ c K O}$; CreER mice had significantly lower PPRs compared with controls (control, $1.7 \pm 0.08, n=13 ;$ LIS1 $^{+/ c K O} ;$ CreER, $1.27 \pm 0.1, n=9 ; p<$ 0.001 , two-tailed $t$ test). Together, these findings are consistent with an increase in excitatory synaptic input to granule cells attributable to a reduction in LIS1 and not as a consequence of disorganized DG architecture.

\section{Discussion}

Medically intractable epilepsy and severe cognitive impairments in patients with MCD emphasizes the importance of identifying mechanisms of aberrant synaptic function in dysplastic hippocampal networks. Cortical hyperexcitability in malformationassociated epilepsies is typically thought to arise as a consequence of abnormal cell positioning (Leventer et al., 2008; Jensen, 2009).
As such, most human and experimental studies have focused on areas containing dysplastic neurons as primary regions of abnormal neuronal migration, improper development, and hyperexcitability. These studies have identified important mechanisms leading to specific neuroanatomical pathologies that interrupt normal stages of cortical development. However, seizures can also arise in human brain regions not classified as disorganized (Wang et al., 2007; Major et al., 2009), and clear evidence for a population of "epileptic" dysplastic neurons has failed to emerge (Cepeda et al., 2003; George and Jacobs, 2011). Using an animal model of human lissencephaly, we show that functional integration of granule cells within the malformed DG is disrupted by LIS1 haploinsufficiency. Mature granule cells exhibit altered synaptic plasticity associated with enhanced glutamatergic synaptic drive. These effects occurred not only in heterozygous LIS1 mutants but also in conditional mutants featuring an absence of neuronal migration disorder in adulthood. This demonstrates, for the first time, that migration disorders produce major alterations in excitatory synaptic transmission independent from defects in neuronal organization. Interestingly, adult-born granule cells ectopically positioned in the molecular layer of heterozygous LIS1 mutants appeared to integrate into the synaptic network more rapidly than newly born granule cells located in the hilus or granule cell layer. The convergence of these features in a mouse model could have significant consequences for circuit information processing and/or contribute to the generation of pathological network excitability associated with type I lissencephaly. 
A number of genetically based animal models of MCD have been developed, and most show robust hyperexcitability and/or spontaneous seizures (Wenzel et al., 2001; Kellinghaus et al. 2004; Patel et al., 2004; Kwon et al., 2006; Harrington et al., 2007; Patrylo and Willingham, 2007; Nosten-Bertrand et al., 2008; Greenwood et al., 2009; Kerjan et al., 2009). When synaptic mechanisms have been investigated, these studies have typically reported postsynaptic alterations in glutamatergic excitatory (Wang et al., 2007; Auerbach et al., 2011; Bateup et al., 2011; Luikart et al., 2011) or GABAergic inhibitory currents (Trotter et al., 2006; Ackman et al., 2009). For example, experimental tuberous sclerosis (TSC), caused by inactivating mutations in the TSCl gene in vivo, is associated with greater postsynaptic AMPA and NMDA receptor-mediated currents, impaired long-term depression, and increased EPSC frequencies in the absence of altered presynaptic release probability (Auerbach et al., 2011; Bateup et al., 2011). In contrast, our results suggest that enhanced excitatory synaptic drive in LIS1 mutants is attributable to enhanced neurotransmitter release. This conclusion is consistent with previous work showing an increase in the excitability of CA1 pyramidal neurons and defects in presynaptic vesicle density in LIS1 mutants (Fleck et al., 2000; Greenwood et al., 2009). The effect of enhanced presynaptic excitation on hippocampal network function is likely significant, because even small changes in excitatory transmission of granule cells might substantially alter synchronized CA3 discharges (Traub and Dingledine, 1990). Identification of a presynaptic deficit could present an opportunity to develop novel treatments for intractable epilepsy disorders associated with a brain malformation, e.g., antiepileptic drugs such as levetiracetam (Yang et al., 2007) that bind to and inhibit transmitter release mechanisms.

Injury-based models of temporal lobe epilepsy produce structural changes, such as interneuron loss (Kobayashi and Buckmaster, 2003) and the formation of new recurrent excitatory connections in the DG (Wuarin and Dudek, 2001; Hunt et al., 2009, 2010). LIS1 mutants do not exhibit interneuron cell loss (Fleck et al., 2000; Jones and Baraban, 2007) or mossy fiber sprouting, but it remains possible that reduced LIS1 function could result in aberrant synaptogenesis or altered dendritogenesis (e.g., an increase in the number of spines) which might have direct effects on excitatory synaptic input independent of robust axonal or laminar disorganization. Fleck et al. (2000) reported the presence of spiny basilar dendrites in a small subpopulation of heterotopic granule cells. This could reflect aberrant synaptogenesis because basilar dendrites are normally present only in developing granule cells, but it is also possible that these cells represent ectopic immature granule cells. Previous work found relatively normal projection patterns of commissural/association fibers in the DG of LIS1 mutants despite abnormal granule cell positioning (Wang and Baraban, 2008), and abnormal recurrent circuits in area CA1 of LIS1 mutants are unlikely (Greenwood et al., 2009). Consistent with these reports, our results suggest that mossy fibers in LIS1 mutants exhibit relatively normal axonal projections toward area CA3. Moreover, we did not find evidence for polysynaptic responses to afferent stimulations or the types of epileptiform burst discharges that accompany recurrent mossy fiber circuits in any mature or newborn granule cell as reported for acquired epilepsy models (Wuarin and Dudek, 2001; Overstreet-Wadiche et al., 2006; Hunt et al., 2009, 2010) or other models of neuronal migration disorder (Wenzel et al., 2001; Patel et al., 2004; Kwon et al., 2006; Patrylo and Willingham, 2007). Therefore, mossy fiber sprouting does not appear to be a contributing factor to the pathology of LIS1 haploinsufficiency, despite significant granule cell displacement, hyperexcitability, and spontaneous seizures in LIS1 mutant mice.

The functional development of newborn granule cells within the normotopically organized adult hippocampus has been well established in normal animals and acquired models of epilepsy (Overstreet et al., 2004; Laplagne et al., 2006). Recent studies revealed septotemporal differences in the rate of granule cell proliferation, survival, and connectivity in the adult hippocampus (Jinno, 2011; Piatti et al., 2011). Surprisingly, our findings reveal that the ectopic position of adult-born granule cells influenced their functional maturation and integration. Newborn ML-EGCs of LIS1 mutants received glutamatergic perforant path input earlier than cells in the granule cell layer or hilus or in wild-type control animals. These neurons appeared to represent a more "intermediate" granule cell (Overstreet-Wadiche and Westbrook, 2006). Although the pattern of newborn granule cell displacement in LIS1 mutants is comparable with models of temporal lobe epilepsy (Parent et al., 1997), these types of heterogeneous domains have not been described previously in normal or pathological conditions. Most studies have focused exclusively on functional changes in ectopic neurons located in the hilus (Scharfman et al., 2000; Zhan and Nadler, 2009; Zhan et al., 2010; Cameron et al., 2011) or the granule cell layer (OverstreetWadiche et al., 2006), and alterations of newborn ML-EGCs in a model mimicking granule cell dispersion seen clinically has not been reported previously. Our findings are different from a previous study that showed EGFP-labeled neurons in the granule cell layer received perforant pathway and recurrent mossy fiber input after pilocarpine-induced seizures (Overstreet-Wadiche et al., 2006). In contrast to this acquired epilepsy model, we found that EGFP-labeled cells in the granule cell layer completely lacked glutamatergic synaptic input in LIS1 mutant mice. Locationspecific differences in afferent input and active firing properties of EGFP cells were observed in the presence of heightened synaptic activity. This suggests that ML-EGCs might functionally integrate more rapidly into existing circuitry as a result of their proximity to perforant pathway input, which normally targets the outer half of the molecular layer, rather than enhanced network activity alone.

It is possible that disruptions in inhibitory tone (e.g., more frequent large-amplitude inhibitory events; Jones and Baraban, 2007) in LIS1 mutants may modify granule cell development in a way that favors more rapid integration of newborn cells in the molecular layer. Synaptic influences over granule cell development are first exclusively GABAergic (Overstreet-Wadiche et al., 2005), and these inhibitory events are thought to play a significant role in neuronal development, maturation, and integration (Ge et al., 2007). Because EGFP is transiently expressed, it is possible that it is simply expressed for longer periods in MLEGCs. However, EGFP-labeled granule cells in wild-type and LIS1 mutants expressed the early neuronal marker DCX. This implies that labeled cells were at a similar developmental age, regardless of cell positioning. Similarly, BrdU pulse-chase labeling showed that the timing of EGFP expression is not affected even in pilocarpine-induced epileptic mice (Overstreet-Wadich et al., 2006). It seems likely that the depolarized resting potentials, relatively high input resistances, and slow membrane time constants of molecular layer EGFP cells compared with fully mature granule cells would promote temporal summation of excitatory input and action potential firing. Therefore, premature incorporation of a subpopulation of ectopically placed newborn neurons into the malformed hippocampal circuitry might support network hyperexcitability. This population of neurons has not been 
recognized previously and could, in concert with the overall enhancement of glutamate-mediated excitation, play a significant role in underlying cognitive and epileptic phenotypes associated with LIS1 haploinsufficiency.

\section{References}

Ackman JB, Aniksztejn L, Crépel V, Becq H, Pellegrino C, Cardoso C, Ben-Ari Y, Represa A (2009) Abnormal network activity in a targeted genetic model of human double cortex. J Neurosci 29:313-327.

Arruda-Carvalho M, Sakaguchi M, Akers KG, Josselyn SA, Frankland PW (2011) Posttraining ablation of adult-generated neurons degrades previously acquired memories. J Neurosci 31:15113-15127.

Auerbach BD, Osterweil EK, Bear MF (2011) Mutations causing syndromic autism define an axis of synaptic pathophysiology. Nature 480:63-68.

Bateup HS, Takasaki KT, Saulnier JL, Denefrio CL, Sabatini BL (2011) Loss of Tscl in vivo impairs hippocampal mGluR-LTD and increases excitatory synaptic function. J Neurosci 31:8862-8869.

Cameron MC, Zhan RZ, Nadler JV (2011) Morphologic integration of hilar ectopic granule cells into dentate gyrus circuitry in the pilocarpine model of temporal lobe epilepsy. J Comp Neurol 519:2175-2192.

Castro PA, Cooper EC, Lowenstein DH, Baraban SC (2001) Hippocampal heterotopia lack functional Kv4.2 potassium channels in the methylazoxymethanol model of cortical malformations and epilepsy. J Neurosci 21:6626-6634.

Cepeda C, Hurst RS, Flores-Hernández J, Hernández-Echeagaray E, Klapstein GJ, Boylan MK, Calvert CR, Jocoy EL, Nguyen OK, André VM, Vinters HV, Ariano MA, Levine MS, Mathern GW (2003) Morphological and electrophysiological chanracterization of abnormal cell types in pediatric cortical dysplasia. J Neurosci Res 72:472-486.

Cowley MA, Smart JL, Rubinstein M, Cerdán MG, Diano S, Horvath TL, Cone RD, Low MJ (2001) Leptin activates anorexigenic POMC neurons through a neural network in the arcuate nucleus. Nature 411:480-484.

Elliott RC, Khademi S, Pleasure SJ, Parent JM, Lowenstein DH (2001) Differential regulation of basic helix-loop-helix mRNAs in the dentate gyrus following status epilepticus. Neuroscience 106:79-88.

Fleck MW, Hirotsune S, Gambello MJ, Phillips-Tansey E, Suares G, Mervis RF, Wynshaw-Boris A, McBain CJ (2000) Hippocampal abnormalities and enhanced excitability in a murine model of human lissencephaly. J Neurosci 20:2439-2450.

Ge S, Pradhan DA, Ming GL, Song H (2007) GABA sets the tempo for activity-dependent adult neurogenesis. Trends Neurosci 30:1-8.

George AL, Jacobs KM (2011) Altered intrinsic properties of neuronal subtypes in malformed epileptogenic cortex. Brain Res 1374:116-128.

Greenwood JS, Wang Y, Estrada RC, Ackerman L, Ohara PT, Baraban SC (2009) Seizures, enhanced excitation and increased vesicle number in Lis1 mutant mice. Ann Neurol 66:644-653.

Harrington EP, Möddel G, Najm IM, Baraban SC (2007) Altered glutamate receptor-transporter expression and spontaneous seizures in rats exposed to methylazoxymethanol in utero. Epilepsia 48:158-168.

Hirotsune S, Fleck MW, Gambello MJ, Bix GJ, Chen A, Clark GD, Ledbetter DH, McBain CJ, Wynshaw-Boris A (1998) Graded reduction of Pafah1b1 (Lis1) activity results in neuronal migration defects and early embryonic lethality. Nat Genet 19:333-339.

Houser CR (1990) Granule cell dispersion in the dentate gyrus of humans with temporal lobe epilepsy. Brain Res 535:195-204.

Hsia AY, Masliah E, McConlogue L, Yu GQ, Tatsuno G, Hu K, Kholodenko D, Malenka RC, Nicoll RA, Mucke L (1999) Plaque-independent disruption of neural circuits in Alzheimer's disease mouse models. Proc Natl Acad Sci U S A 96:3228-3233.

Hunt RF, Scheff SW, Smith BN (2009) Posttraumatic epilepsy after controlled cortical impact injury in mice. Exp Neurol 215:243-252.

Hunt RF, Scheff SW, Smith BN (2010) Regionally localized recurrent excitation in the dentate gyrus of a cortical contusion model of posttraumatic epilepsy. J Neurophysiol 103:1490-1500.

Jacobs J, Levan P, Châtillon CE, Olivier A, Dubeau F, Gotman J (2009) High frequency oscillations in intracranial EEGs mark epileptogenicity rather than lesion type. Brain 132:1022-1037.

Jensen FE (2009) Introduction-epileptogenic cortical dysplasia: emerging trends in diagnosis, treatment, and pathogenesis. Epilepsia 50 [Suppl 9]:1-2.

Jinno S (2011) Topographic differences in adult neurogenesis in the mouse hippocampus: a stereology-based study using endogenous markers. Hippocampus 21:467-480.

Jones DL, Baraban SC (2007) Characterization of inhibitory circuits in the malformed hippocampus of Lis1 mutant mice. J Neurophysiol 98:2737-2746.

Jones DL, Baraban SC (2009) Inhibitory inputs to hippocampal interneurons are reorganized in Lis1 mutant mice. J Neurophysiol 102:648-658.

Kawamoto S, Niwa H, Tashiro F, Sano S, Kondoh G, Takeda J, Tabayashi K, Miyazaki J (2000) A novel reporter mouse strain that expresses enhanced green fluorescent protein upon Cre-mediated recombination. FEBS Lett 470:263-268.

Keller BU, Konnerth A, Yaari Y (1991) Patch clamp analysis of excitatory synaptic currents in granule cells of rat hippocampus. J Physiol 435:275-293.

Kellinghaus C, Kunieda T, Ying Z, Pan A, Lüders HO, Najm IM (2004) Severity of histopathologic abnormalities and in vivo epileptogenicity in the in utero radiation model of rats is dose dependent. Epilepsia 45:583-591.

Kempermann G, Kuhn HG, Gage FH (1997) More hippocampal neurons in adult mice living in an enriched environment. Nature 386:493-495.

Kerjan G, Koizumi H, Han EB, Dubé CM, Djakovic SN, Patrick GN, Baram TZ, Heinemann SF, Gleeson JG (2009) Mice lacking doublecortin and doublecortin-like kinase 2 display altered hippocampal neuronal maturation and spontaneous seizures. Proc Natl Acad Sci USA 106:6766-6771.

Kobayashi M, Buckmaster PS (2003) Reduced inhibition of dentate granule cells in a model of temporal lobe epilepsy. J Neurosci 23:2440-2452.

Kwon CH, Luikart BW, Powell CM, Zhou J, Matheny SA, Zhang W, Li Y, Baker SJ, Parada LF (2006) Pten regulates neuronal arborization and social interaction in mice. Neuron 50:377-388.

Laplagne DA, Espósito MS, Piatti VC, Morgenstern NA, Zhao C, van Praag H, Gage FH, Schinder AF (2006) Functional convergence of neurons generated in the developing and adult hippocampus. PLoS Biol 4:e409.

Leventer RJ, Guerrini R, Dobyns WB (2008) Malformations of cortical development and epilepsy. Dialogues Clin Neurosci 10:47-62.

Li H, Prince DA (2002) Synaptic activity in chronically injured, epileptogenic sensory-motor neocortex. J Neurophysiol 88:2-12.

Liu M, Pleasure SJ, Collins AE, Noebels JL, Naya FJ, Tsai MJ, Lowenstein DH (2000) Loss of BETA2/NeuroD leads to malformation of the dentate gyrus and epilepsy. Proc Natl Acad Sci U S A 97:865-870.

Luikart BW, Schnell E, Washburn EK, Bensen AL, Tovar KR, Westbrook GL (2011) Pten knockdown in vivo increases excitatiory drive onto dentate granule cells. J Neurosci 31:4345-4354.

Major P, Rakowski S, Simon MV, Cheng ML, Eskandar E, Baron J, Leeman BA, Frosch MP, Thiele EA (2009) Are cortical tubers epileptogenic? Evidence from electrocorticography. Epilepsia 50:147-154.

Millar AG, Bradacs H, Charlton MP, Atwood HL (2002) Inverse relationship between release probability and readily releasable vesicles in depressing and facilitating synapses. J Neurosci 22:9661-9667.

Min MY, Asztely F, Kokaia M, Kullmann DM (1998) Long-term potentiation and dual-component quantal signaling in the dentate gyrus. Proc Natl Acad Sci U S A 95:4702-4707.

Mori-Kawakami F, Kobayashi K, Takahashi T (2003) Developmental decrease in synaptic facilitation at the mouse hippocampal mossy fibre synapse. J Physiol 553:37-48.

Nosten-Bertrand M, Kappeler C, Dinocourt C, Denis C, Germain J, Phan Dinh Tuy F, Verstraeten S, Alvarez C, Métin C, Chelly J, Giros B, Miles R, Depaulis A, Francis F (2008) Epilepsy in Dcx knockout mice associated with discrete lamination defects and enhanced excitability in the hippocampus. PLoS One 3:e2473.

Overstreet LS, Hentges ST, Bumaschny VF, de Souza FS, Smart JL, Santangelo AM, Low MJ, Westbrook GL, Rubinstein M (2004) A transgenic marker for newly born granule cells in dentate gyrus. J Neurosci 24:3251-3259.

Overstreet-Wadiche LS, Westbrook GL (2006) Functional maturation of adult-generated granule cells. Hippocampus 16:208-215.

Overstreet-Wadiche LS, Bromberg DA, Bensen AL, Westbrook GL (2005) GABAergic signaling to newborn neurons in dentate gyrus. J Physiol 94:4528-4532.

Overstreet-Wadiche LS, Bromberg DA, Bensen AL, Westbrook GL (2006) Seizures accelerate functional integration of adult-generated granule cells. J Neurosci 26:4095-4103.

Pandey JP, Smith DS (2011) A cdk5-dependent switch regulates lis1/ndel1/ 
dynein-driven organell transport in adult axons. J Neurosci 31:17207-17219.

Parent JM, Yu TW, Leibowitz RT, Geschwind DH, Sloviter RS, Lowenstein DH (1997) Dentate granule cell neurogenesis is increased by seizures and contributes to aberrant network reorganization in the adult rat hippocampus. J Neurosci 17:3727-3738.

Patel LS, Wenzel HJ, Schwartzkroin PA (2004) Physiological and morphological characterization of dentate granule cells in the p35 knock-out mouse hippocampus: evidence for an epileptic circuit. J Neurosci 24:9005-9014.

Patrylo PR, Willingham A (2007) Anatomic and electrophysiologic evidence for a proconvulsive circuit in the dentate gyrus of reeler mutant mice, an animal model of diffuse cortical malformation. Dev Neurosci 29:73-83.

Paylor R, Hirotsune S, Gambello MJ, Yuva-Paylor L, Crawley JN, WynshawBoris A (1999) Impaired learning and motor behavior in heterozygous Pafahlb1 (Lis1) mutant mice. Learn Mem 6:521-537.

Piatti VC, Davies-Sala MG, Espósito MS, Mongiat LA, Trinchero MF, Schinder AF (2011) The timing for neuronal maturation in the adult hippocampus is modulated by local network activity. J Neurosci 31 : $7715-7728$.

Pleasure SJ, Collins AE, Lowenstein DH (2000) Unique expression patterns of cell fate molecules delineate sequential stages of dentate gyrus development. J Neurosci 20:6095-6105.

Pramparo T, Libiger O, Jain S, Li H, Youn YH, Hirotsune S, Schork NJ, Wynshaw-Boris A (2011) Global developmental gene expression and pathway analysis of normal brain development and mouse models of human neuronal migration defects. PLoS Genet 7:e1001331.

Reiner O, Carrozzo R, Shen Y, Wehnert M, Faustinella F, Dobyns WB, Caskey CT, Ledbetter DH (1993) Isolation of a Miller-Dicker lissencephaly gene containing $\mathrm{G}$ protein $\beta$-subunit-like repeats. Nature 364:717-721.

Scharfman HE, Goodman JH, Sollas AL (2000) Granule-like neurons at the hilar/CA3 border after status epilepticus and their synchrony with area CA3 pyramidal cells: Functional implications of seizure-induced neurogenesis. J Neurosci 20:6144-6158.

Staley KJ, Otis TS, Mody I (1992) Membrane properties of dentate gyrus granule cells: comparison of sharp microelectrodes and whole cell recordings. J Neurophysiol 67:1346-1358.

Szabadics J, Varga C, Brunner J, Chen K, Soltesz I (2010) Granule cells in the CA3 area. J Neurosci 30:8296-8307.

Tashiro A, Makino H, Gage FH (2007) Neurogenesis: a critical period during an immature stage. J Neurosci 27:3252-3259.
Tauck DL, Nadler JV (1985) Evidence of functional mossy fiber sprouting in hippocampal formation of kainic acid-treated rats. J Neurosci 5:1016-1022.

Traub RD, Dingledine R (1990) Model of synchronized epileptiform bursts induced by high potassium in CA3 region of rat hippocampal slice. Role of spontaneous EPSPs in initiation. J Neurophysiol 64:1009-1018.

Trotter SA, Kapur J, Anzivino MJ, Lee KS (2006) GABAergic synaptic inhibition is reduced before seizure onset in a genetic model of cortical malformation. J Neurosci 26:10756-10767.

Wang Y, Baraban SC (2007) Granule cell dispersion and aberrant neurogenesis in the adult hippocampus of an LIS1 mutant mouse. Dev Neurosci 29:91-98.

Wang Y, Baraban SC (2008) Aberrant dentate gyrus cytoarchitecture and fiber lamination in Lis1 mutant mice. Hippocampus 18:758-765.

Wang Y, Greenwood JS, Calcagnotto ME, Kirsch HE, Barbaro NM, Baraban SC (2007) Neocortical hyperexcitability in a human case of tuberous sclerosis complex and mice lacking neuronal expression of TSC1. Ann Neurol 61:139-152.

Wenzel HJ, Robbins CA, Tsai LH, Schwartzkroin PA (2001) Abnormal morphological and functional organization of the hippocampus in a p35 mutant model of cortical dysplasia associated with spontaneous seizures. J Neurosci 21:983-998.

Wuarin JP, Dudek FE (2001) Excitatory synaptic input to granule cells increases with time after kainate treatment. J Neurophysiol 85:1067-1077.

Wynshaw-Boris A, Pramparo T, Youn YH, Hirotsune S (2010) Lissencephaly: mechanistic insights from animal models and potential therapeutic strategies. Semin Cell Dev Biol 21:823-830.

Xu-Friedman MA, Regehr WG (2004) Structural contributions to shortterm synaptic plasticity. Physiol Rev 84:69-85.

Yang XF, Weisenfeld A, Rothman SM (2007) Prolonged exposure to levetiracetam reveals a presynaptic effect on neurotransmission. Epilepsia 48:1861-1869.

Zhan RZ, Nadler JV (2009) Enhanced tonic GABA current in normotopic and hilar ectopic dentate granule cells after pilocarpine-induced status epilepticus. J Neurophysiol 102:670-681.

Zhan RZ, Timofeeva O, Nadler JV (2010) High ratio of synaptic excitation to synaptic inhibition in hilar ectopic granule cells of pilocarpine-treated rats. J Neurophysiol 104:3293-3304.

Zhou FW, Roper SN (2011) Altered firing rates and patterns in interneurons in experimental cortical dysplasia. Cereb Cortex 21:1645-1658. 